\title{
History and Applications of Dust Devil Studies
}

\author{
Ralph D. Lorenz ${ }^{1}$ Matthew R. Balme ${ }^{2}$ - Zhaolin Gu ${ }^{3}$ Henrik Kahanpää4 \\ Martina Klose $^{5,6}$ • Michael V. Kurgansky ${ }^{7}$ Manish R. Patel ${ }^{2,8}$ • Dennis Reiss ${ }^{9}$. \\ Angelo Pio Rossi ${ }^{10}$ - Aymeric Spiga ${ }^{11}$ - Tetsuya Takemi ${ }^{12}$ - Wei Wei ${ }^{13}$
}

Received: 12 September 2015 / Accepted: 2 February 2016 / Published online: 4 April 2016

(C) The Author(s) 2016. This article is published with open access at Springerlink.com

\begin{abstract}
Studies of dust devils, and their impact on society, are reviewed. Dust devils have been noted since antiquity, and have been documented in many countries, as well as on the planet Mars. As time-variable vortex entities, they have become a cultural motif. Three major stimuli of dust devil research are identified, nuclear testing, terrestrial climate studies, and perhaps most significantly, Mars research. Dust devils present an occasional safety hazard to light structures and have caused several deaths.
\end{abstract}

R.D. Lorenz

ralph.lorenz@jhuapl.edu

1 Johns Hopkins University Applied Physics Laboratory, Laurel, MD 20723, USA

2 Open University, Walton Hall, Milton Keynes, MK7 6AA, UK

3 Xi' an Jiaotong University, Xi'an, Shaanxi 710049, China

4 Finnish Meteorological Institute, 00101 Helsinki, Finland

5 Institute for Geophysics and Meteorology, University of Cologne, Pohligstr. 3, 50969 Cologne, Germany

6 Present address: USDA-ARS Jornada Experimental Range, Las Cruces, NM 88003, USA

7 A.M. Obukhov Institute of Atmospheric Physics, Russian Academy of Sciences, Pyzhevsky 3, 119017 Moscow, Russia

8 Space Science and Technology Department, STFC Rutherford Appleton Laboratory, Didcot, Oxfordshire OX11 0QX, UK

9 Institut für Planetologie, Westfälische Wilhelms-Universität, Wilhelm-Klemm-Str. 10, 48149 Münster, Germany

10 Department of Physics and Earth Sciences, Jacobs University Bremen Campus Ring 1, 28759 Bremen, Germany

11 Laboratoire de Meteorologie Dynamique (LMD), 4 place Jussieu, 75252, Paris cedex 5, France

12 Disaster Prevention Research Institute, Kyoto University, Uji, Kyoto 611-0011, Japan

13 Wuhan University of Technology, Wuhan, Hubei 430063, China 


\section{Introduction}

"And so the hours dragged by until the sun stood dead above our heads, a huge white ball in the noon sky, beating, blazing down, and then it happened-suddenly, a whirlwind! Twisting a great duststorm up from the earth, a black plague of the heavens filling the plain, ripping the leaves off every tree in sight, choking the air and sky. We squinted hard and took our whipping from the gods."

Thus speaks a sentry in the play 'Antigone', written by Sophocles in Greece around 450 BCE (e.g. Bowker 2011), capturing a scene that many dust devil researchers two and a half millennia later will doubtless appreciate. Dust devils are therefore a phenomenon that has been documented for as long as there has been documentation of anything, and short of finding a prehistoric sketch of a dust devil on a cave wall, appears to be the first meteorological report in the West of this phenomenon.

In the present paper, we review the history of dust devil research in various countries, and its motivations, and then the history of research on dust devils on Mars. We then survey the applications of dust devil research, and finally note the role of dust devils as a motif in culture. First, however, we offer some definitions and distinctions against other vortex structures, and note the designation of dust devils in different languages.

Dust devils are dry convective vortices, rendered visible by lofted dust (Fig. 1). The definition offered by Oke et al. (2007a) is succinct: "A vortex rotating in either direction faster than its motion downwind. It must have a coherent columnar or cone shape extending in a vertical direction above the surface. It must carry dust to a height of at least $1 \mathrm{~m}$ and last for at least $10 \mathrm{~s}$. It is distinct from a dust blow in that it maintains a fast rotating coherent structure with vertical extension and distinct from a small dust whirl in its size and duration." Usually the instability is generated by strong solar heating, although cold air masses over warm ground may cause them. Vortices generated by purely mechanical forcing (that can for example also loft snow or leaves in conditions without strong heating) such as those caused by outflows from mesoscale convective systems (e.g. gustnados) are not usually considered to be dust devils, although this chapter will occasionally stray beyond the narrowest definition. Where such outflows are cold (as is often the case in desert storms due to evaporative cooling), however, the distinction is less clear cut. Related phenomena include fire whirls associated with forest fires and the like, where flames may be collimated in narrow rotating columns.

Fig. 1 Image of a dust devil in Arizona, observed in a NASA field campaign. The large dust devil has a small 'little brother' to the right. Credit: NASA/U. of Michigan

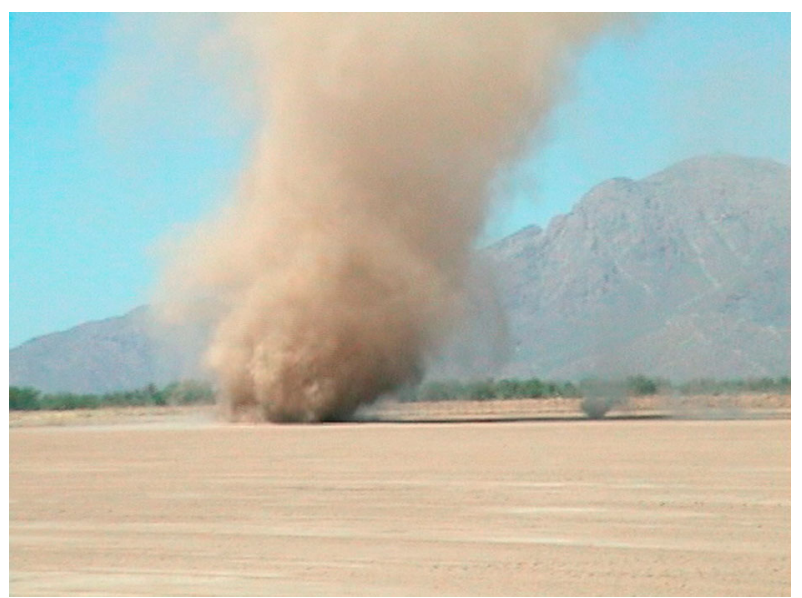


Table 1 Terms for dust devils. Note that the Navajo word should not be used in casual conversation as it often has evil connotations in that culture. Note also some remarks in the Culture section at the end of this paper

\begin{tabular}{|c|c|c|}
\hline Location/language & Name & Etymology, Other remarks \\
\hline Australia & Willy-willy & $\begin{array}{l}\text { Aboriginal/onomatopoeic? } \\
\text { sometimes 'Whirly-whirl' }\end{array}$ \\
\hline Arabic & Djinn & Spirit, devil (qv the anglicized form 'genie') \\
\hline Japan & Jin-sen-pu & Dust whirlwind. Also tsumuji-kaze 'whirlwind' \\
\hline France & $\begin{array}{l}\text { Tourbillon de poussière } \\
\text { Diable de poussière } \\
\text { Trombe de sable }\end{array}$ & $\begin{array}{l}\text { Dust whirl } \\
\text { Dust devil } \\
\text { Sand trumpet (archaic) }\end{array}$ \\
\hline Germany & $\begin{array}{l}\text { Staubwirbel } \\
\text { Kleintrombe } \\
\text { Sandhose } \\
\text { Wirbelwind } \\
\text { Staubteufel }\end{array}$ & $\begin{array}{l}\text { Dust whirl } \\
\text { Small trumpet } \\
\text { Sand hose } \\
\text { Whirlwind } \\
\text { Dust devil (most common) }\end{array}$ \\
\hline Russia & $\begin{array}{l}\text { pyl'niy (peschaniy) vikhr' } \\
\text { пыльный вихрь }\end{array}$ & Dust (sand) whirl \\
\hline China & 尘卷风 & Dust whirl \\
\hline India & Suntargalis or devva & Devil wind \\
\hline Navajo & Chiindii & Spirit \\
\hline Spanish (inc. Americas) & $\begin{array}{l}\text { diablo de polvo } \\
\text { demonio de polvo } \\
\text { remolino de polvo } \\
\text { burro }\end{array}$ & $\begin{array}{l}\text { Dust devil } \\
\text { Dust demon } \\
\text { Dust whirl } \\
\text { (Donkey) }\end{array}$ \\
\hline Italian & $\begin{array}{l}\text { diavolo di sabbia } \\
\text { (diavolo di polvere) }\end{array}$ & Dust Devil (Sand Devil) \\
\hline
\end{tabular}

Tornados, while of interest because of some dynamical vortex similarities (see e.g. the chapter by Kurgansky et al. in this volume) are quite distinct from dust devils in that their driving energy is from latent heat in moisture rather than sensible heat. Further, tornados are invariably associated with clouds, from which the vortex descends, whereas dust devils most usually occur in clear sky conditions and the visible structure grows upwards from the ground. Tornados and dust devils may have similar aspect ratios (height/diameter) but tornados are almost always much larger than dust devils, and are usually much more intense (in terms of core pressure drop and wind speed). Waterspouts are essentially tornado-like, in being usually associated with cloud, although they are often similar to dust devils in size.

Hurricanes (and other cyclonic storms such as typhoons) have very much larger horizontal and vertical scales than dust devils, and rather smaller aspect ratios. The large horizontal scale leads to significant effects of planetary rotation (i.e. the Coriolis effect) which is negligible for dust devils. While associated with moist convection, hurricanes do have the feature that like dust devils, much of their energy is supplied at their base (and similar heat engine formalisms can be applied to the generation of mechanical energy in each), and there may be some analogies in the migration paths and vortex structure.

\subsection{Dust Devil Terminology}

Table 1 summarizes the terms used for dust devils in different languages. Clearly some terms are simply descriptive of the phenomenon ('dust whirl(wind)'), some are onomatopoeic, and 
Fig. 2 The cumulative growth of the corpus of dust devil work in refereed journals in the ADS abstract database (http://adsabs. harvard.edu/). Note the slope change around 2003, and the jump circa 1970

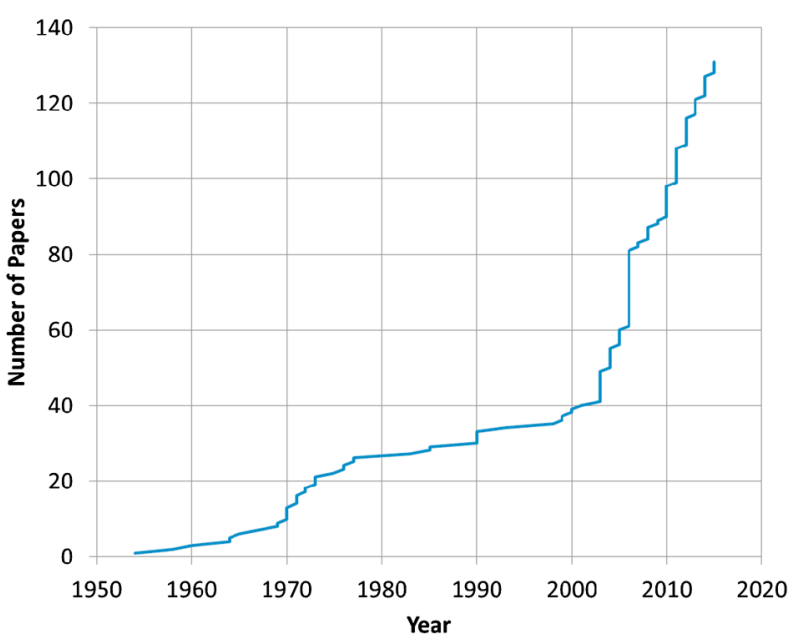

some invoke the ephemeral/aethereal nature of them with reference to spirits or devils. It is of interest that the shape-inspired term 'trombe' appears in early French and German literature (sharing a root with the English 'trombone') but has largely fallen into disuse.

\subsection{Scientific Significance of Dust Devil Studies}

It is the general impression of the authors that the public finds dust devils 'interesting', a qualitative endorsement of the utility of their study. However, the scientific level of interest can be at least crudely quantified. An informal bibliometric study, searching for refereed journal papers with "Dust devil" in the title in the Smithsonian Physics/Astronomy database found some 131 papers 1930-2015. It is recognized that this database will not capture all the literature (particularly that in languages other than English), but it can be considered representative.

Figure 2 shows the cumulative number of papers versus time- -it is seen that papers accumulate at the rate of about $1.5 / \mathrm{yr}$ until the early 21 st century when there is an abrupt change in slope - essentially reflecting studies of dust devils on Mars as an ongoing enterprise- to $\sim 4$ /yr. There is also a flurry of activity in the late 1960s/early 1970s reflecting work in the USA (see later). The particular jump in 2006 largely reflects a special issue of the journal Geophysical Research Letters that published papers discussed at a workshop devoted to dust devils hosted in Flagstaff, Arizona by Ronald Greeley in August 2005.

An inspection of the most-cited papers in this corpus (Table 2) attests to the importance of Mars discoveries, with half of the 'top 10' papers referring to Mars directly.

\section{History of Dust Devil Studies—Earth}

\subsection{Overview}

Dust devils are found (Fig. 3) in many parts of the world, although predominantly in desert regions. While dust devils have been reported from antiquity, their serious study began in the mid-19th century with the onset of global scientific exploration and growing commercial activity by the European powers: see the following sections on Britain, France and Germany. 
Table 2 The most widely-cited dust devil papers (Harvard-SAO Database Title Search 'Dust Devil')

\begin{tabular}{llrl}
\hline Year & Authors & Citations & Title \\
\hline 1985 & Thomas \& Gierasch & 120 & Dust Devils on Mars \\
1998 & Renno et al. & 93 & A Simple Thermodynamical Theory for Dust Devils \\
1999 & Metzger et al. & 85 & Dust Devil Vortices Seen by the Mars Pathfinder Camera \\
1983 & Ryan \& Lucich & 79 & Possible Dust Devils - Vortices on Mars \\
1960 & Freier & 71 & The Electric Field of a Large Dust Devil \\
1970 & Kaimal \& Businger & 71 & Case Studies of a Convective Plume and a Dust Devil \\
1973 & Sinclair & 71 & The Lower Structure of Dust Devils \\
2006 & Balme \& Greeley & 67 & Dust Devils on Earth and Mars \\
1969 & Sinclair & 61 & General Characteristics of Dust Devils \\
2003 & Greeley et al. & 58 & Martian Dust Devils: Laboratory Simulations \\
\hline
\end{tabular}

Fig. 3 Map of reported dust devil studies or sightings (black stars, not all historical reports included) in reports cited in this paper-note the predominance around $30^{\circ}$ latitude, where the downwelling branch of the Hadley circulation leads to generally dryer conditions. Grey stars denote undocumented sightings by the present authors (UAE and Ethiopia) and their correspondents (Svalbard, Botswana)

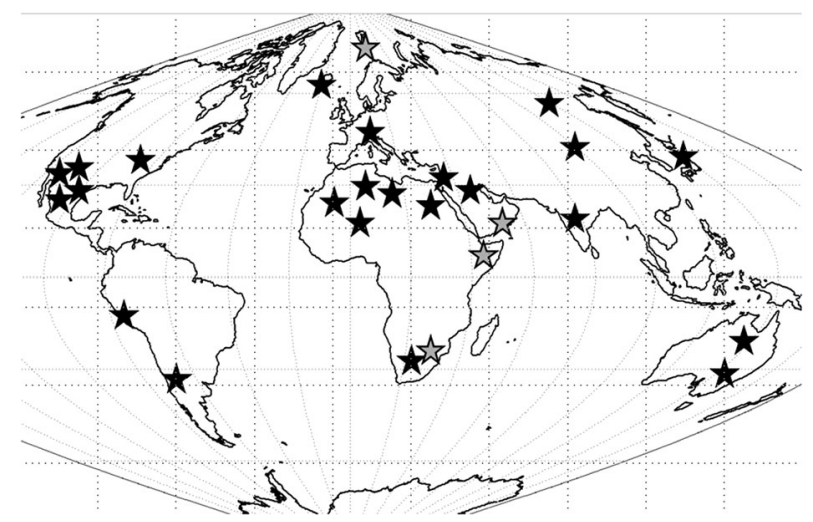

In the 20th century, most scientific activity on dust devils was in the USA, a situation that broadly holds today. More recently, interest in dust devils has grown, in part due to environmental concerns, in Japan and China.

Dust devils would likely have remained a minor topic in meteorology, but for the Cold War. Specifically, nuclear weapons testing is typically conducted in desert areas for the obvious reason that these have low populations. Since dust devils might transport radioactive dust from these remote sites, some work on dust devils may have been sponsored by relevant agencies to assess this hazard (for example, Snow and McLelland's work sponsored by the US Defense Nuclear Agency) (Snow and McClelland 1990).

A second impetus to dust devil studies has been the exploration of Mars. While we review Mars dust devil work as an integrated whole in the next section, the impact of Mars exploration on dust devil research generally in different countries is noted here-work circa 1970 seems in part to have been associated with Mars and the US Viking program. The growing role of Europe in planetary exploration, with Mars Express, Beagle 2, and various proposed missions and involvements in NASA missions, has similarly stimulated dust devil research in other countries. In what follows we arrange the countries approximately by chronology of their first contributions to dust devil studies.

Note that it is not the purpose of this paper to comprehensively review all publications on dust devils. Some representative references from various countries and on various topics are 
identified only as a starting point. Other chapters in the present volume explore the literature more fully, and a useful overall review is Balme and Greeley (2006).

\subsection{Italy and the Roman Empire}

As our opening quotation suggests, the often dry and hot conditions around the Mediterranean Sea can yield dust. In military campaigns a cloud of dust kicked up by a marching or galloping army was often the earliest indication of its approach. Julius Caesar's various chronicles make only scant mention of dust raised by the wind, but Lucan's Pharsalia (an epic poetical account of the Roman Civil War, Lucanus, 65 C.E., 1926) has the following graphic account which offers a number of meteorological insights:

"Libya has no mountains to oppose the rising wind and break its force, no cliffs to drive it back and scatter it, or to turn its hurricane to clear breezes; it does not fall upon forests and wear itself out by bending ancient oaks: all the land is level, and the wind travels freely and wreaks the fury of Aeolus all over the desert. There is no rain in the cloud of whirling dust which it drives furiously in circles; most of the land is lifted up by it and is suspended in the air, as the eddying motion is continuous. The needy Nasamonian sees his possessions flying in the wind and his dwelling blown to pieces; the Garamantian is laid bare, and his hut, beginning with the roof, is snatched away and flies aloft. Fire does not carry what it seizes to a greater height: as high as smoke may rise up and mar the face of day, so great is the dust that fills the air. And now, even fiercer than its wont, the wind attacked the Roman column; and the staggering men can find no footing on the sand, when even the spot they tread on is carried away. If Africa had a solid framework, so that the heavy weight of its cliffs might confine the South wind within hollow caverns, the wind would overset the whole world and wrench it from its foundations; but because the soil is easily driven about with its drifting sands, it remains stable by offering resistance at no point, and the lower stratum stands fast because the upper is dispersed. Driving furiously, the blast snatched up the men's helmets and shields and javelins, and rushed on, carrying them through the mighty void of heaven."

Clearly, this account may conflate dust/sand storms with dust devils, but it clearly notes the vortical motion characteristic of dust devils, and the fact that these strong motions are not associated with rainfall. Active saltation is described, and in addition to helmets and javelins being lofted, damage to structures is noted. Beyond these dramatic observations, some strikingly perceptive thoughts can be perceived-there is a hint that smoke plumes and dust reach the same height (both capped by the Planetary Boundary Layer, perhaps), and an argument that the low aerodynamic roughness of the African continent may enhance the ferocity of its winds.

After Roman times, the most notable studies are those by Leonardo da Vinci on vortices in general. He suggests colliding winds generate vorticity, and observed the following (Atalay and Wamsley 2009), which could perhaps be a tornado or waterspout rather than a dust devil:

"It often happens that, when one wind meets another at an obtuse angle, these two winds circle around together and twine themselves into the shape of a huge column; and having thus condensed, the air acquires wright. I once saw such winds, raging around together, produce a hollow in the sand of the seashore as deep as the height of a man, removing from it stones of considerable size, and carrying sand and seaweed through the air for the space of a mile and dropping them in the water, whirling them around and transforming them into a dense column, which formed dark thick clouds at its upper extremity."

In connection with waterspouts in Italy, it may be noted that the young British scientist Michael Faraday wrote an interesting account of them while traveling with Humphrey Davy 


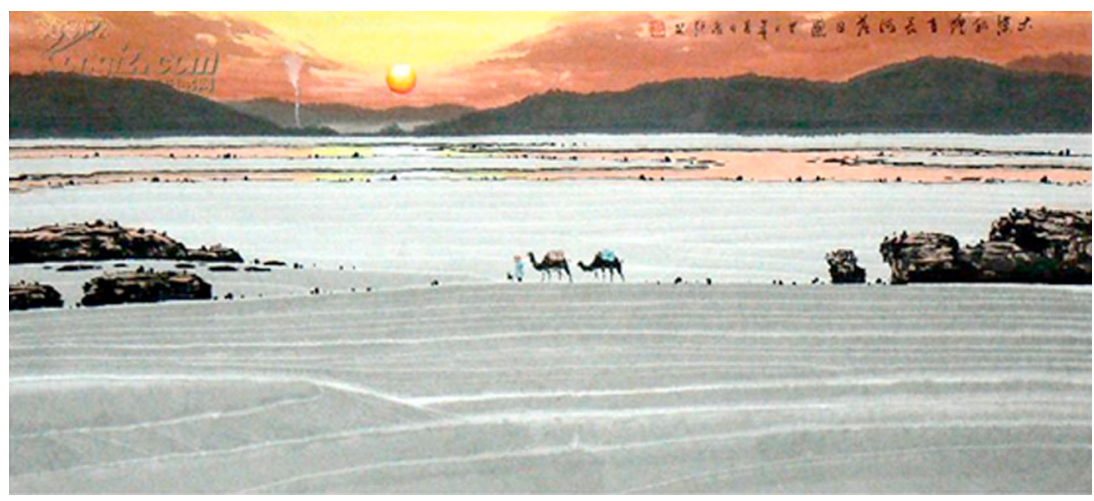

Fig. 4 Dust devil depicted in Chinese ancient Poem thirteen centuries ago (drawn by Quanzong Zhang). Note that the dust column flares into a plume at the top, and occurs rather near sunset

in that country - his correspondence with Baddeley on dust devils is reported in that author's 1860 book.

As elsewhere, Mars exploration has stimulated terrestrial dust devil studies in Italy, and Rossi and Marinangeli (2004) reported the first observation of terrestrial counterparts to Martian dust devil tracks, in Niger.

\subsection{China}

In the year 737 C.E. (Kaiyuan 25th year, Tang Dynasty), the well-known ancient poet Wei Wang traveled to the frontier at the emperor's order. He wrote the famous poem On Mission to the Frontier after viewing the spectacular scenery on the way. In the poem, the sentence "A plume of smoke rises up into the evening sky of the Great Desert, while the Yellow River dimmed as the setting sun goes down" depicted the view of vast boundless desert and endless river (as shown in Fig. 4). In fact, the "smokes" mentioned in the sentence may be interpreted as the dust and sand lofted in the swirling winds of a dust devil.

China has extensive desert regions, especially in its north and west (see Fig. 5), and aeolian studies and efforts to mitigate the effects of sand dune migration on agricultural areas and infrastructure such as railway lines have become extensive, with research institutes devoted to aeolian studies. Sandstorms frequently occur in northern China (as many as 20 days a year in Mongolia), especially in Spring. In one recent example, in March in 2000, large sandstorms attacked Inner Mongolia and the Beijing district, with winds reaching force 8 or 9 (on the Beaufort scale, i.e. 17-24 m/s). Seven workers who worked in a two-floor building were blown down and two of them were killed.

As for dust devils, specifically, before the 21 st century, there were only cursory studies. Le (1983) compiled the diurnal variation of 193 dust devils that occurred in Taklimakan Desert from 1964 to 1970. According to the data of Lei et al. (2005), during 1971-2000, 594 dust devils occurred in Shaanxi Province. Dust devils in these two places had some common characteristics. They began appearing after 9 a.m., became frequent in 12:00-15:00 (local time) and then declined. Before 8 a.m. And after 18:00, no dust devils occurred.

More recently, theoretical and simulation work has been pursued: e.g. Gu et al. (2006, 2010) simulated the formation process of dust devils with LES (Large Eddy Simulation) methods as a function of swirl ratio, and used an Euler-Lagrange approach to simulate the gas-solid two-phase flows of dust devils in the convective boundary layer. Gu et al. (2013) 
Fig. 5 Spatial distribution and the occurrence days per year of sandstorms in China

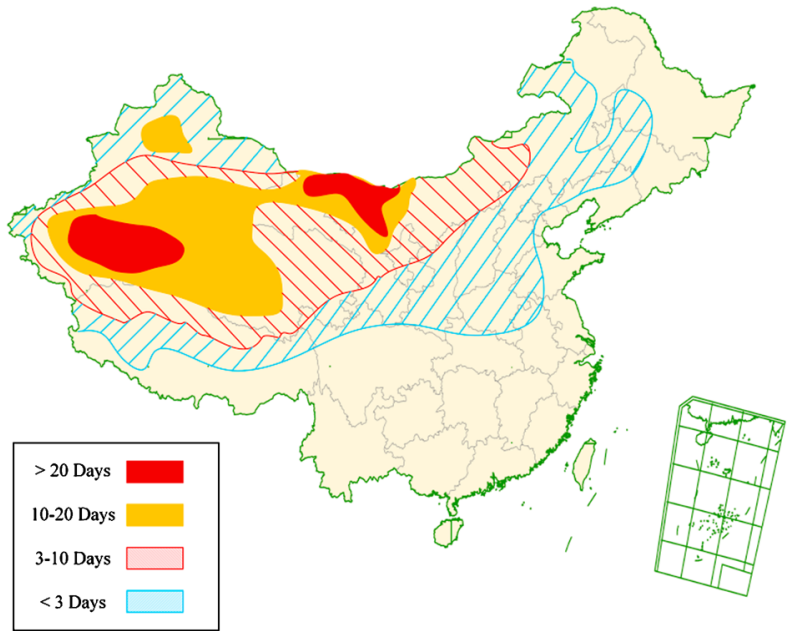

demonstrated a charging mechanism of sand particles with the adsorbed water on microporous surfaces of wind-blown sand, recognizing the mobility of water ions $\mathrm{H}^{+} / \mathrm{OH}^{-}$between the contacting sand grains with a temperature difference. Much of this work was aggregated in a book on these topics (Gu 2010). Additionally, the Turpan desert in Western China was the site of the first in-situ examination of dust devil tracks on Earth (Reiss et al. 2011a, 2011b).

\subsection{Britain and the British Empire}

While the cold and damp United Kingdom does not commonly have circumstances favorable to dust devil formation, many territories formerly under British administration have desert areas that do. Most notably these include North Africa, the Middle East, and Australia. The dispersal of soldiers, officials and other professionals across the globe, together with a strengthening tradition of reporting observations, created the opportunity for careful studies of dust devils beginning in the mid-1800s. It is of note that in the same period, the same motivations prompted the Royal Navy to commission "A Manual of Scientific Enquiry; prepared for the use of Officers in Her Majesty's Navy and Travellers in General", edited by the astronomer John Herschel (and including a chapter on meteorology by him, and one on geology by Charles Darwin). The Meteorology chapter (Herschel 1851) instructs readers on the care and use of meteorological instruments, and the careful recording of their measurements. It gives particular guidance on observations of whirlwinds:

'All circumstances from the first trace or prognostic to their final dissipation should be minutely noticed... At what distance is the whirling motion of the air perceptible? What are the indications of the barometer during their approach and recess? Do any and what electrical phenomena accompany them.'

A century and a half later, this remains good advice for dust devil study, on any planet.

Baddeley (1860), a surgeon in the Bengal Army, compiled an entire book, much of which is on the topic of dust devils- "Whirlwinds and Dust Storms of India: An Investigation into the Law of Wind and Revolving Storms at Sea". This appears to be one of the first detailed investigations published on dust devils.

The book struggles to develop a unified theory for vortical winds (such as cyclones as well as dust devils), and noting a number of electrical phenomena associated with dust devils 
makes the suggestion (erroneously) that electric forces are in fact the cause of the winds. This notion aside, the book usefully documents many visual observations of dust devils and storms in the vicinity of Lahore (now in modern Pakistan) including their ascent to more than $2000 \mathrm{ft}$, and the frequent presence of multiple cores. He notes the striking similarity of the multiple co-rotating cores to the motion of dancing Dervishes (an analogy repeated by others), and hints at a possible origin of this religious dance from the motion of dust devils:

"This remarkable sight gives the idea of a fairy dance round a ring; and the motions are from all accounts, exactly imitated by the dancing Dervishes of Turkey; one of their holy exercises being to whirl round and round like a top; singly, or in company with several others, performing at the same time a gyration round in a circle, as if their dance originated in the very phenomenon now described."

He describes following on foot one dust devil for a mile, then being able to penetrate the centre and walk along inside it-he notes "The centre was perfectly calm, while round about, the winds were blowing in every direction".

A casual sentence in the book (p. 81), noting electrical activity associated with dust devils observed with a gold-leaf electroscope and other means, makes the observation (13th October 1850) that a solution of starch and potassium iodide rapidly become discolored. Although the report does not offer any explanation or interpretation, it seems clear in retrospect that this is evidence of atmospheric oxidants, and specifically ozone, and anticipates by almost 150 years the consideration of dust devil oxidants in atmospheric chemistry on Mars. It may be noted that ozone was only discovered in 1840 (and so it may have been a 'hot topic' at the time) and that the starch-iodide reaction was developed soon thereafter as a specific test.

Various reports appear in the scientific and popular media of the period, documenting dust devils and other storms in various parts of the empire, notably India and South Africa. In the Straits Times, "Dust devils in India, Observations Made of Curious Phenomena", a report is made of observations of dust devils near Agra. Weather reports had predicted thunderstorms in the local area, which never manifested, and it was observed that "Numerous very large dust devils were forming during the middle of the day" instead. These dust devils were categorized to range in size from 20-100 $\mathrm{m}$ in diameter, in some cases exceeding $800 \mathrm{~m}$ in height. A curious observation was that of one dust devil that was noted to pause over a village for approximately 10 minutes, with no perceptible translational movement. Such stability and lack of movement is rare in dust devils and implies extremely quiescent ambient wind conditions, and though the reported static duration may potentially be somewhat exaggerated, it represents a rare observation of a stable, non-moving dust devil. The journalist also reported observing varying rates of rotation and dust vertical flux (assumed to be from visual observation), along with irregular masses of dust being raised in the vicinity of the base of the dust devil, resembling a "dust curtain" extending some $50 \mathrm{~m}$ from the dust devil itself, which was attributed to a descending current from just outside the limit of the upwelling dust column.

While not a meteorologist, it is worth noting William Rankine, a Scottish engineer who contributed significantly to the development of thermodynamics and its application to steam engine performance in the mid-late $1800 \mathrm{~s}$. Vortices figure prominently in his thinking, and his idealized model of a vortex (which like a temperature scale, and an engine cycle, bear his name) is often used in dust devil studies.

Little further British work on dust devils is of note until an important contribution by Flower (1936), a meteorologist working in Egypt for the Air Ministry (it is tempting to speculate whether Flower ever met or worked with Ralph Bagnold, in the same part of the empire at the same time; Bagnold was a desert soldier and pioneer in aeolian studies, his 
1941 book 'Physics of Blown Sand and Desert Dunes' remains required reading today). Flower's tabulations of dust devil diameters, heights, longevity etc. remain one of the most comprehensive visual datasets, and were recently used to develop analytic correlations of diameter and longevity (Lorenz 2013).

As evidenced above, the UK has a long tradition in meteorological research, but while dust-raising in general and its impact on climate has been a current research topic, dust devils in particular have not received much 'mainstream' interest. Only a few reports of dust devil vortices appear in British journals, often from other parts of the (former) empire (e.g. Libya and Cyprus, McGinnigle 1966, 1970).

However, dust devil work in the 21 st century at UK institutions was stimulated by the development of the Beagle 2 Mars lander, and the prospect of detecting dust devils in-situ on that mission. Some examples include a re-analysis of Viking data (Ringrose et al. 2003), consideration of the 'Delta-P effect' (Balme and Hagermann 2006), instrumentation trials and field measurements in Nevada (Mason et al. 2014), and analysis of Mars orbital imaging (Towner 2009).

\subsection{Germany}

The interdisciplinary research of Alexander von Humboldt opened new avenues in many branches of the natural sciences. From one of Humboldt's journeys to Southern America (Orinoco area), he offers what is likely one of the earliest 'scientific' reports on dust devils (von Humboldt 1849):

"When under the vertical beam of the never-cloudy sun the charred grass layer has crumbled into dust, the hardened surface gapes open as if it would be shaken by strong quakes. When it is then touched by opposing air flows, whose quarrel balances through rotating movement, the plain allows a peculiar view. In the form of funnel shaped clouds with their tips sliding across the surface, sand rises vapor-like through the air-thin, electrically charged center of the whirl: similar to the rushing waterspouts that are feared by experienced skippers."

Other early reports about dust devils in German literature include observations in what is now Iraq by Schläfli (1870) who noted that small dust devils are frequent especially during summer. Early dust devil observations in Germany were also reported by Less (1891) and Budde (1883). The inventor of the photographic flash, Adolf Miethe (Miethe 1899) reported about ash devils (Aschehosen) in the Luneburg Heath in Lower Saxonia. These ash devils formed due to manmade peat fires; sometimes 20-50 per hour were observed with heights of 200-300 m. The author notes that the ash devils travel at speeds and in directions of the prevailing winds, and the formation ceased at wind speeds above $\sim 3.5 \mathrm{~ms}^{-1}$.

While better-known for his theory of continental drift, the meteorologist, polar explorer and geoscientist Alfred Wegener made an interesting report (Wegener 1914) of dust devils on a lava plain, Odàđahraun, in Iceland, noting that he had previously only once seen a $\sim 20 \mathrm{~m}$ high dust devil on a hot summer day in Marburg, Germany. During their stay in Iceland in mid-June 1912, Wegener and his company saw 20-30 dust devils at a time on the wide plain with typical diameters of about 5-10 $\mathrm{m}$ and heights of more than $100 \mathrm{~m}$. Wegener got the notion that dust devil height would be of the same order as the stratocumulus cloud base. In addition to dust devils, Wegener and his colleague frequently observed non-rotating convective plumes, which developed into dust devils and gave some insight into dust devil formation. Wegener notes that the dark volcanic sand would effectively absorb the solar heat, driving the formation of convective vortices. This report may be one of the highest-latitude field reports of dust devils and is quite widely cited thereafter, notably in Geiger's textbook 
'The Climate Near the Ground' (1950). In this book, Geiger describes dust devils formed near Erlangen in southern Germany, where air flowing over a cliff edge induces vorticity causing devils on a heated chalky plain. Geiger notes an audible whistling of the devils, and goes on to summarize Flower's (1936) observations.

Letzmann (1939) aimed to facilitate a comprehensive investigation of dust devils by suggesting guidelines for the observations of atmospheric vortices, including dust devils. Among the focuses he suggests are shape, duration, track, atmospheric conditions, pressure changes and surface conditions, many of which are still used to characterize dust devils today.

Lammert (1947) summarizes an intensive period of dust devil occurrence in advance of a thunderstorm on a summer day in northern central Germany (Salzderhelden, Lower Saxony). Few minutes before the thunderstorm began, numerous (50-60 in total, 4-7 at a time) dust devils with 3-5 m diameter and heights of hundreds of meters occurred and lifted "whistling and howling corkscrew-like" considerable amounts of sediment. According to eye-witness reports, the dust devils were superseded by a dust storm generated by the convective downdrafts associated with the thunderstorm. The event came to an end with the starting rain.

Apart from natural dust devil occurrences in Germany (e.g. Koschmieder 1951), Maurer (1934) observed an interesting man-made dust devil. In May 1934, a group of about 30 young girls met on a sandy sports field in eastern Germany (Schwarza, Thuringia). As exercise, they were instructed to run in circles of about $15 \mathrm{~m}$ diameter. After four rounds, a dust devil began to form at the inside of the circle, grew to about $5 \mathrm{~m}$ height, left the field, and ceased quickly. Maurer emphasized the strong heating over sun exposed surfaces such as the sports field.

Recent papers on dust devils by German scientists have included some work on Large Eddy Simulation (e.g. Raasch and Franke 2011), and field measurements of dust-lifting in the Morroccan desert (Ansmann et al. 2009). The development of the High-Resolution Stereo Camera (HRSC), and its arrival at the Red Planet in 2003 on Mars Express stimulated significant work on remote observation of Martian dust devils (e.g. Stanzel et al. 2008; Reiss et al. 2011b) as well as terrestrial dust devil tracks (e.g. Reiss et al. 2010, 2011b, 2013).

\subsection{France}

The situation of historical dust devil reports in France is rather similar to Germany and the United Kingdom. Most of France itself is not prone to the formation of dust devils; convective vortices might occur on very hot summer days, especially in Southern France, but dusty material to be carried within the vortices are rarely available to form proper dust devils. As with the United Kingdom, opportunities to report dust devils arose when France administered colonies in North Africa and Central Asia, and soldiers, merchants, and travellers used to report observations of desert environments they were exploring in the middle of the nineteenth century. Other reports were based on observations in arid regions in America (e.g. Mexico, reports by M. Virlet d'Aoust) not under French administration.

Dust devils were usually reported as either anecdotical features within a broader exploration report, or as an additional dusty example in the taxonomy of natural vortices (as in the book by Zurcher and Margoller (1876) 'Trombes et Cyclones', which cites Baddaley's work). However, following the development of the French meteorological network in the late 1850 s and $1860 \mathrm{~s}$, the interest for meteorological phenomena became more and more prominent amongst French scientists. Reports about dust devils started to be a matter of scientific interest, with questions arising about their properties and formation. 
Fig. 6 A French woodcut from the 19th century 'Trombes de Sable dans la Steppe', showing the threatening aspect of large dust devils, perhaps like those reported by Prejevalski

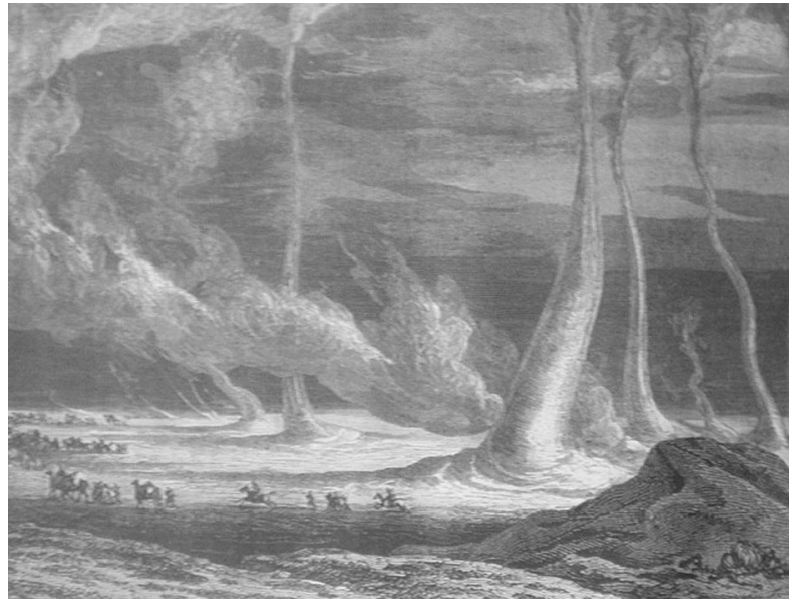

For instance, in a June 1883 report to the Comptes Rendus de l'Académie des Science, Colonel Prejevalski ${ }^{1}$ writes: "The various morphologies of dust devils are reminiscent of marine vortices: dust is transported upward, often in a spiraling motion". This description of a dust devil within an exploration report written by a military traveler (likely in Central Asia-see Fig. 6) is typical of what was proposed at the time. However, it is notable that this report is not simply describing the occurrence of dust devils and their morphology: it proposes an analogy with another natural whirling phenomena, and describes the dust transport within the dust devil. This report led M. Faye, who authored several other discussions about dust devils in Comptes Rendus de l'Académie des Sciences and Annuaire du Bureau des Longitudes since 1877 , to publish a report in the same journal to severely criticize Colonel Prejevalski's observations.

According to him, those "simply cannot be regarded as a scientific document worth being published in the Comptes Rendus"! M. Faye then explains that dust devils, similarly to tornados, find their swirling motion originating from regional-scale vorticity (thus comes from above the boundary layer rather than from the surface), and this motion when it finally gets down to the surface would cause dust lifting. He concludes that what Colonel Prejevalski reports about the apparent motion of dust within a dust devil is an illusion, one of the same kind that led sea men to conclude that marine vortices would pump water from the surface to the higher atmosphere. M. Faye might be right for marine tornados, but we now know he had a wrong interpretation about dust devils, while Colonel Prejevalski is completely in line with modern observations of those phenomena. This discussion in the French literature parallels analogous debates about cyclones and other weather systems in (at least) Britain and America in the 19th century.

Recent dust devil research in France, like that in Germany, the UK and Italy, has been stimulated by climate studies and interest in dust-lifting in general, and by studies of the meteorology of Mars. The emphasis there has been on numerical simulation, e.g. Spiga and Forget (2009), although the French development of a seismometer instrument for the InSight Mars lander to be launched in 2016 may stimulate new observational studies.

\footnotetext{
${ }^{1}$ Although mentioned here since the discussion is in the French literature, in fact Nikolai Przhevalsky (transliterations of the Cyrillic vary) was a Russian geographer who explored Central and East Asia, which is presumably where his familiarity with dust devils arose. A wild horse species in that region is named after him.
} 


\subsection{United States of America}

Although widespread familiarity with dust devils awaited the modern settlement of the desert Southwest, dust devils were recognized among the pantheon of rotating winds in William Ferrel's ${ }^{2}$ discussion of cyclones and tornados (Ferrel 1881), where he describes 'sand spouts'. That work is notable in recognizing that the centripetal acceleration of the sand and dust must be generated somehow, and he ascribes it to the radial drag of the inrushing winds. Further, he suggests that since the drag on each particle varies as its diameter squared, while the required force varies as diameter cubed, 'particles of sand of different sizes arrange themselves at different distances from the center', an important insight.

Although the Eastern part of the USA does not often encounter dust devils, having a more damp and temperate climate than the west, one of the earliest reports of dust devils was made there by Benjamin Franklin in Maryland (Franklin 1755). The report is remarkable not only in its observational detail, but also for Franklin's experiment in modifying the devil.

'It appeared in the form of a sugar-loaf, spinning on its point, moving up the hill towards us... its smaller part near the ground appeared no bigger than a common barrel, but widening upwards, it seemed at 40 or 50 feet high, to be 20 or 30 feet in diameter... I followed it, riding close by its side, and observed its licking up, in its progress, all the dust that was under its smaller part. As it is a common opinion that a shot, fired through a water-spout, will break it, I tried to break this little whirlwind, by striking my whip frequently through it, but without any effect.... Soon after, it quitted the road and took into the woods, growing every moment larger and stronger, raising, instead of dust, the old dry leaves with which the ground was thick covered, and making a great noise with them and the branches of the trees, bending some tall trees round in a circle swiftly and very surprisingly, though the progressive motion of the whirl was not so swift but that a man on foot might have kept pace with it; but the circular motion was amazingly rapid. By the leaves it was now filled with, I could plainly perceive that the current of air they were driven by, moved upwards in a spiral line; and when I saw the trunks and bodies of large trees invelop'd in the passing whirl, which continued intire after it had left them I no longer wondered that my whip had no effect on it in its smaller state. I accompanied it about three quarters of a mile, till some limbs of dead trees, broken off by the whirl, flying about and falling near me, made me more apprehensive of danger; and then I stopped, looking at the top of it as it went on, which was visible, by means of the leaves contained in it, for a very great height above the trees. Many of the leaves, as they got loose from the upper and widest part, were scattered in the wind; but so great was their height in the air, that they appeared no bigger than flies.

My son, who was by this time come up with me, followed The whirlwind till it left the woods, and crossed an old tobacco-field, where, finding neither dust nor leaves to take up, it gradually became invisible below as it went away over that field. The course of the general wind then blowing was along with us as we travelled, and the progressive motion of the whirlwind was in a direction nearly opposite, though it did not keep a strait line, nor was its progressive motion uniform, it making little sallies on either hand as it went, proceeding sometimes faster and sometimes slower, and seeming sometimes for a few seconds almost stationary, then starting forward pretty fast again.'

In addition, the following observation by Thomas Jefferson, a farmer and careful recorder of meteorological phenomena as well as principal author of the Declaration of Independence, is of interest as being a likely description of dustless vortices (Jefferson 1787):

\footnotetext{
${ }^{2}$ The meridional circulation 'Ferrel cell' is named after this meteorologist.
} 
Going out into the open air, in the temperate, and in the warm months of the year, we often meet with bodies of warm air, which, passing by us in two or three seconds, do not afford time to the most sensible thermometer to seize their temperature. Judging from my feelings only, I think they approach the ordinary heat of the human body. Some of them perhaps go a little beyond it. They are of about 20 or 30 feet diameter horizontally. Of their height we have no experience; but probably they are globular volumes wafted or rolled along with the wind. But whence taken, where found, or how generated? They are not to be ascribed to Volcanos, because we have none. They do not happen in the winter when the farmers kindle large fires in clearing up their grounds. They are not confined to the spring season, when we have fires which traverse whole counties, consuming the leaves which have fallen from the trees. And they are too frequent and general to be ascribed to accidental fires. I am persuaded their cause must be sought for in the atmosphere itself, to aid us in which I know but of these constant circumstances; a dry air; a temperature as warm at least as that of the spring or autumn; and a moderate current of wind. They are most frequent about sun-set; rare in the middle parts of the day; and I do not recollect having ever met with them in the morning.

Dust devils occur in dry areas of the USA outside the Southwest, as in this observation of multiple vortices rotating around a common column in South Carolina (Anonymous 1902):

"It consisted of four separate whirlwinds which followed each other to the left around the center of a circle 10 or 15 feet in diameter, like horses going around a horse power thrashing machine. The whole circle also seemed to be moving to the left and around the center of an enlarging coil. The motion was made apparent by dust taken up from the soil, and it could not well be seen above 10 or 15 feet from the ground. Sometimes one or more of the small whirls would rise so as not to be visible, but presently it would touch the soil again in its regular place in the procession. This beautiful and curious motion continued for five minutes or more over a spot only about 100 feet in diameter. It then advanced northward the four whirls enlarging their circle to about 75 yards and then vanishing."

Ives (1947) wrote a review of dust devils, recording his own observation of dust devils in the Bonneville salt flats in Utah, one lasting some seven hours and traveling 40 miles. He also notes that dust devils can be started sometimes by driving a jeep across, or firing a shell into, the 'lake' in a mirage. Mirages require strongly superheated air, which is unstable to convection, so these anecdotes make sense. He speculates that activity of small animals might therefore trigger many dust devils - although this was obviously before the discovery of dust devils on Mars.

He also summarizes some in-situ measurements of meteorological quantities, and noted reports that rabbits and hares can be lofted by dust devils, implying updrafts of $35 \mathrm{mph}$ or more. He notes that such encounters were usually fatal to the animals involved, although he observed himself kangaroo rats falling from devils (and surviving). He then deduced (by dropping such rats from a tower and measuring their terminal velocity) the corresponding updraft velocities as $25 \mathrm{mph}$, recording memorably that the animal was "apparently unhurt, although usually very angry".

Wyett (1954) reported a dust devil encounter at the airport in St. George, Utah, wherein the pressure drop was recorded by a barograph (see Fig. 7). Several papers emerge in the 1950s and 1960s on electric fields in dust devils, as well as on analytic models of dust devil vortices and considerations of their energetics. There is not space for a full review herethe reader is referred to other papers in this volume, and to an earlier review by Balme and Greeley (2006).

Many recognize the pivotal role of Peter C. Sinclair in dust devil research. Sinclair was a research student in the Atmospheric Sciences department at the University of Arizona in 
Fig. 7 Perhaps one of the first instrumental records of a dust devil encounter (arrowed), after Wyett (1954). The barograph scale is in inches of mercury - the 0.04 inch drop corresponds to $\sim 1.4 \mathrm{hPa}$

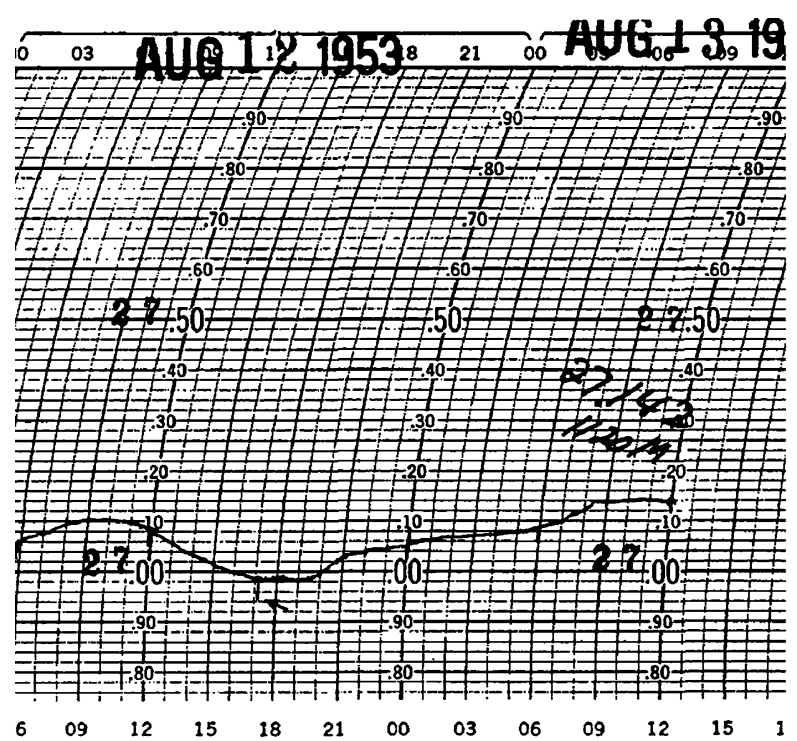

Tucson, and generated some of the first usefully-robust statistics on dust devil occurrence and properties, as well as pioneering the active "chase and sample" methodology. A preliminary report (Sinclair 1964) captures the highlights of his work, initially using a hand-carried mobile observing station (Fig. 8).

Around the time of Sinclair's early work, an important survey was conducted by Lambeth (1966) of the Army Electronics Command at the White Sands Missile Range in New Mexico. This survey lasted May-September, using a linear array of six recording stations. When a human operator saw a dust devil, chart recorders were activated. Only 21 events were recorded in the five months of operation, a rather modest haul. Lambeth concludes with the suggestion that "dust devils can be measured in adequate numbers only by using mobile sensors".

Sinclair had by this time started to make many encounters using an impressive jeepborne meteorology tower (Fig. 9), as well as measurements in a sailplane of the dust plumes atop dust devil. Sinclair's papers $(1965,1969,1973)$ and thesis are well worth reading even today, noting such challenges as the high-speed data acquisition required on a hot, dusty, bouncing jeep in the desert (a cine camera recorded film of instrument readings!). Sinclair also performed a couple of visual surveys from fixed stations, data still referred to today.

It is of note that Sinclair's work was funded by the Office of Naval Research (ONR), although it is not obvious whether this had any connection with nuclear testing, or was merely one of many areas of fundamental research supported by the US Defense Department.

At this point space exploration and dust devil meteorology begin to intersect. J.A. Ryan, at the Missile and Space Systems Division of the Douglas Aircraft Corporation, speculated (Ryan 1964) that transient winds associated with 'a cyclonic system (somewhat analogous to a terrestrial dust devil)' might be responsible for the yellow clouds, presumed to be of dust, that had been seen telescopically on Mars. Later, Ryan and J. Carroll (then of the 'Space Sciences Division' of McDonnell-Douglas: the space program now allowed the progressively-consolidating aerospace industry to employ their own scientists, a situation that unfortunately is not widespread today) with NASA funding published several papers on field observations of dust devils in the Mojave desert in California, with a fixed meteorological station (e.g. Ryan and Carroll 1970). They appear to have been more lucky than 
Fig. 8 Peter Sinclair with his portable measurement station with rather prominent anemometer and wind vane (from his Ph.D. thesis). The box with electrical dial is a sensitive microbarometer designed by Sinclair

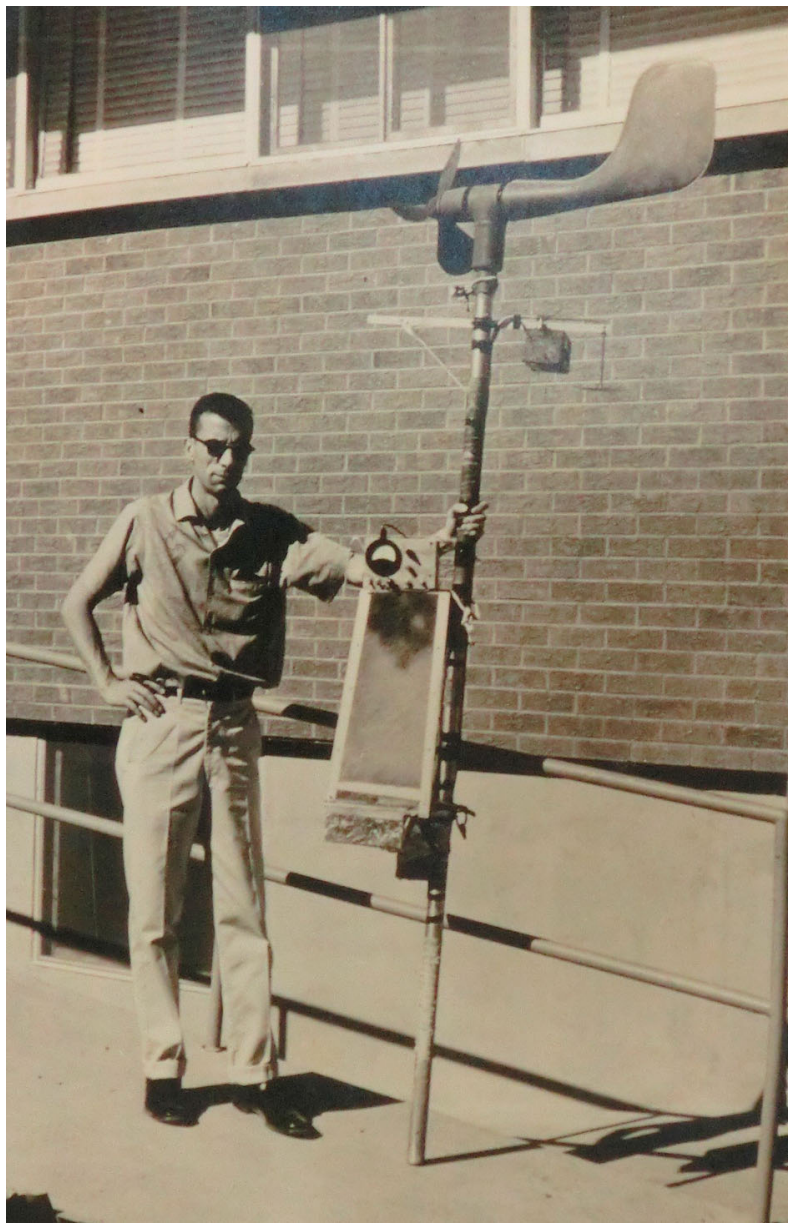

Lambeth, observing 80 dust devils in just a few weeks, but they helped make their own luck by 'grooming' the surface around their mast to ensure dust availability.

After the early 1970s, dust devil research declined somewhat - a notable exception being Snow and McLelland's survey at White Sands (New Mexico) in the late 1980s, funded by the Defense Nuclear Agency_until the resurge stimulated by Mars Pathfinder in the late 1990s (Metzger et al. 1999). Several field campaigns took place, in Eloy (between Phoenix and Tucson, Arizona) and at ElDorado Playa near Boulder City (just outside Las Vegas, Nevada), in many instances in order to trial instruments for the aborted Mars 2001 lander in a campaign called MATADOR (e.g. Tratt et al. 2003), for Beagle 2, the Mars Science Laboratory and other projects.

\subsection{Australia}

As a large, arid country, Australia sees frequent dust devil activity, and a local Aboriginal term is frequently adopted-“willy-willy". Some notable researches have been stimulated there. The Australian Civil Aviation Authority (Bell 1969) noted that dust devils can present an appreciable hazard to light aircraft (which are an important means of transport and com- 


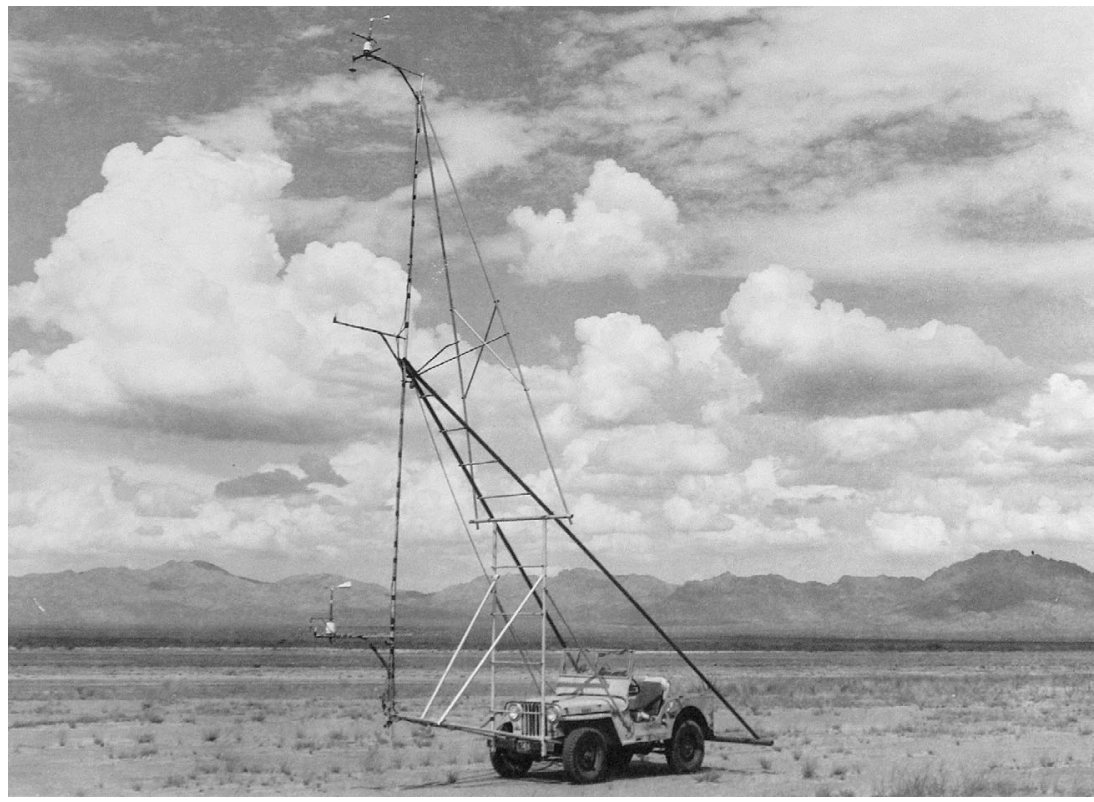

Fig. 9 Arizona desert west of Tucson, with Peter Sinclair's mobile meteorology tower mounted on the surplus jeep he used to penetrate dust devils (from Sinclair's Ph.D. thesis)

munication, given Australia's large distances) and Spillane and Hess (1988) reviewed dry convective activity and its role in air accidents. Hess and Spillane (1990) reviewed the characteristics of dust devils in Australia, drawing on aviation reports, and noted that devils tend to ascend to a fraction ( 0.1 to 0.5$)$ of the boundary layer height. They also suggested a condition of dust devil formation- $h / L>50$, where $h$ is the boundary layer height and $L$ the Obukhov length (this type of condition may have originated with Deardorff in the USA). More recently, Oke et al. (2007a, 2007b) conducted a field study of dust devils, the most extensive reported since Snow and McLelland. Beyond dust devils proper, it may be noted that Australia's partly vegetated drylands (the "Bush") are subject to periodic wildfires, and these often produce quite prominent fire devils. Also related are observations by Hess et al. (1988), who identified convection-driven updrafts that they proposed are similar to dust devils, although they occurred over Port Phillip Bay in Victoria, Australia when cool air was advected over warm water.

Recently, the signatures of dust devil vortices were identified in infrasound (i.e. highpass-filtered pressure) signals at a Comprehensive Test Ban Treaty Organization (CTBTO) monitoring site at Wurramunga in Australia's Northern Territory (Lorenz and Christie 2015).

\subsection{Japan}

Although there are no deserts or arid regions in the Japanese islands, dust devils are sometimes reported on fine days especially in warm seasons. They commonly occur over sandpaved playgrounds in schools and in sports fields, because strong surface heating under fine-weather conditions generates intense thermals locally. An example was reported in Tachikawa and Deguchi (1987) who showed that a whirlwind blew away a tent over the playground in an elementary school during a sports festival at the school in October 1986. 
(a)

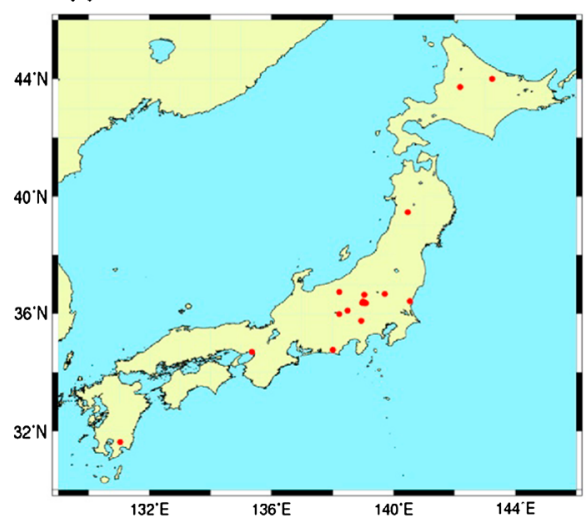

(b)

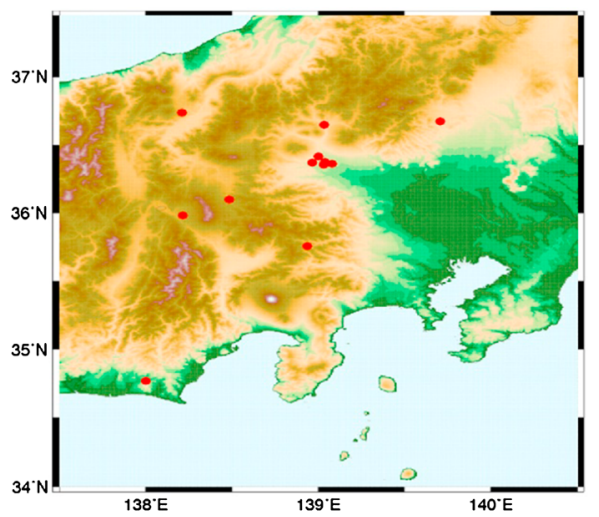

Fig. 10 The locations of dust devil occurrence in Japan from 1961 to 2009, based on JMA database. (a) The locations over the Japanese island, and (b) those in the central part of Japan

The Japan Meteorological Agency (JMA) archives the information on tornados and other gust events that occur in Japan on the web (http://www.data.jma.go.jp/obd/stats/data/bosai/ tornado/index.html). Based on an inspection of this database for the present paper, it is found that there were 18 recorded occurrences of dust devils from 1961 to 2009 in Japan. Figure 10a exhibits the locations of dust devil occurrence in Japan during this time period. More frequent occurrence is seen in the central part of Japan. Figure 10b shows an enlarged map corresponding to a central part of Japan. Note that this JMA database is not comprehensive, because the information is obtained by field investigations by JMA officials after the events. For example, the event reported by Tachikawa and Deguchi (1987) is not included in the JMA's database. Although the JMA's database does not provide full coverage for the dust-devil occurrence in Japan, the geographical features shown in Fig. 10 seem to be consistent with the notion that dust devils favorably occur in the inland regions in Japan.

Since dust devils have typically a micro-scale (typically on the order of $1 \mathrm{~m}$ ) with a very short lifetime (on the order of 10 seconds to a few minutes), direct meteorological observations of such events are very rare. The impacts of dust devils in Japan are not significant; however, damages such as shown in Tachikawa and Deguchi (1987) are notable. There are sometimes newspaper reports typically in the warm season every year on the occurrence of damage due to gusty winds produced by dust devils.

Recently remote-sensing techniques have become a powerful tool for measuring microscale vortices including dust devils in Japan. Inoue et al. (2011) successfully detected vortices such as tornados and mesocyclones, although not dust devils, during a winter storm event with the use of a low-level scanning X-band Doppler radar. Fujiwara et al. (2011, 2012) used a three-dimensional scanning Doppler lidar to detect dust-devil-like vortices that develop in the daytime under fair-weather convective conditions over an urban area. They revealed that invisible dust devils frequently occur from long-term observations. Doppler lidar was also used to detect an otherwise-invisible small-scale vortex over the sea i.e. a waterspout (Fujiwara and Fujiyoshi 2014). Ito and Niino (2014) applied a Particle Image Velocimetry (PIV) method to estimate the wind field in a dust devil which they encountered in Arizona, USA. They estimated the maximum tangential wind in the dust devil as $16 \mathrm{~m} \mathrm{~s}^{-1}$. 


\subsection{Russia, Canada, Argentina, Chile, Denmark and Other Countries}

In Russia dust (sand) devils regularly occur over its southern arid and semi-arid parts spanning Kalmykia, Dagestan and Astrakhan regions (over the lowland north-west from the Kaspian Sea), and also over steppe territories in Voronezh and Rostov regions, and others. In particular, pilots flying over Kalmykia on light airplanes often observe high vertical dust columns associated with dust devils. Dust devils are observed in Kazakhstan, now an independent state, especially near the semi-dried Aral Sea. The observations by Przevalsky in the 1800 s (reported in the 'France' section) were likely made in central Asia. Kennan (1886) describes 'great whirling columns of sand, 100-150 ft in height swept slowly and majestically across the sun-scorched plain' in the Kirgis steppes in Western Siberia.

A dust devil was observed (Roland Neuber, AWI Potsdam, personal communication to $\mathrm{MK}$ ) in Svalbard in the late spring after snow and ice melting and forming a clear spot of dry sandy land, over which the dust devil developed: at $78^{\circ} \mathrm{N}$, this observation is more poleward than that of Wegener in Iceland, and we have recorded it in Fig. 2.

In Chile dust devils occur in the north in the Atacama Desert and likely in the extreme south in Patagonia. In the Atacama Desert the dust devil activity was regularly reported by local people and also by travelers across the desert but the first regular field campaign to study dust devils was organized only in 2008-2009 (Kurgansky et al. 2011). A remarkable site was chosen near the settlement of Huara (about $50 \mathrm{~km}$ from the city of Iquique) with its unprecedented level of dust devil activity (up to more than 60 dust devils visible simultaneously in a $360^{\circ}$ panorama). A site near Huara is also famous for its petroglyphs, the largest in South America. Etymologically the naming Huara is usually attributed to the star (with the reference to aimara language), but by an alternative version, it might be related to the dust devil, which is so frequent there. The Huara dust-devil field campaign was the second one on the South America sub-continent (historically, the first dust-devil field study in the South America of which we are aware is by Metzger et al. (2010)).

Recently, Lorenz and Radebaugh (2016) report observations of abundant dust devils at very high elevations $(3600 \mathrm{~m}$ ) in the Argentine Puna (a plateau somewhat southeast of, but higher than, the Atacama and Altiplano). The Campo Pedro Pomez site at which they measured several intense dust devils is the boundary between a plain of giant gravel ripples, and a field of yardangs carved in volcanic ash (ignimbrite) - a magnificent interplay of aeolian processes. Their report provides some circumstantial evidence that this site has quantitatively (2.5-10x) higher frequencies of dust devil occurrence than low-altitude sites like Eldorado. It may be noted, however, that over a century ago the Scottish astronomer Charles Piazzi-Smyth documented (Piazzi-Smyth 1858) several dust devil encounters, 'being peppered with little pebbles... almost blinded by dust' at an elevation of about $3000 \mathrm{~m}$ in Tenerife, while exploring its volcanic mountains as possible sites for astronomical observatories.

The development of meteorological instrumentation, which is generally rather small and affordable, for Mars landers opened the way for some countries with modest budgets to contribute to dust devil studies: in particular, Finland, Denmark and Canada contributed pressure sensors, a wind indicator and a lidar respectively to the Phoenix mars lander mission, stimulating several papers. More recently Finland and Spain have contributed to the instrumentation on the Curiosity rover, although so far rather few dust devils have been seen. One report of a dust devil in Canada exists, in sub-arctic Labrador at $65^{\circ} \mathrm{N}$ (Grant 1949).

Finally, although we are unaware of detailed reports on dust devils in Peru and Niger, there have been studies of dust devil tracks in those countries (e.g. Rossi and Marinangeli 2004; Hesse 2012 and Reiss et al. 2013). Additionally, the authors of this paper have seen dust devils in Ethiopia and the United Arab Emirates, and have heard of them in Botswana. 
Fig. 11 Viking Orbiter 2 image (ID 038B25) from September 1976 at $72 \mathrm{~m} /$ pixel showing several dust devils with their shadows, the illumination coming from the bottom of the image. The crater is about $19 \mathrm{~km}$ in diameter. Image center is Latitude $40.4^{\circ} \mathrm{N}$ Longitude $215.0^{\circ} \mathrm{E}$. The solar elevation was about 45 degrees, so the shadow length indicates many plumes were several $\mathrm{km}$ high. Viking images including this one were studied by Thomas and Gierasch (1985). The regular-spaced black dots are reseau marks to correct for geometric distortion in the vidicon camera

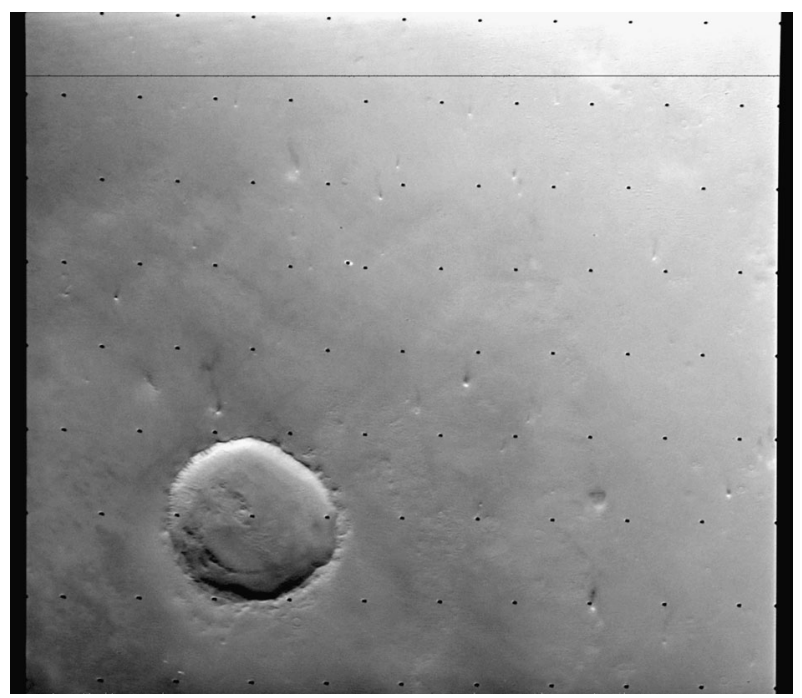

\section{History of Dust Devil Studies-Mars}

The existence of dust devils on Mars was proposed well before any direct evidence for their presence was acquired, both Neubauer (1966) and Gierasch and Goody (1973) predicting that Mars' arid surface, lack of cloud cover and large diurnal temperature variations should provide excellent opportunities for the presence of dust loaded convective vortices. Even before those works, Ryan (1964) had made relevant speculation about the formation of 'yellow clouds'.

Indirect confirmation of these predictions came first from meteorology data sent back by the Viking 2 lander. In their analysis of the Viking 2 wind speed, wind direction and temperature data Ryan and Lucich (1983) showed that excursions in these parameters could be fit by models of convective vortices passing over or near the lander. More than a hundred such encounters were noted, although only a few were thought to be sufficiently intense that they could have lifted sediments and become visible dust devils. Visual confirmation of the presence of dust devils on Mars would await the results of analysis of images returned by the Viking Orbiter spacecraft, more than five years after the missions themselves had come to an end-Thomas and Gierasch (1985) finally presented observations (see Fig. 11) of columnar dust clouds on the martian surface that provided convincing evidence for the presence of dust devils on Mars.

Observations of active martian dust devils were also made from the surface, first by the Mars Pathfinder mission (Metzger et al. 1999) and then in large numbers by the Mars Exploration Rover (MER) "Spirit" mission (Greeley et al. 2006, 2010). (Note that the Viking lander 'camera' was a facsimile imager which took many minutes to scan the scene, and so was not suitable for acquiring pictures of fast-moving objects like dust devils: famously the image of a tortoise in ground tests was smeared by its motion-e.g. Mutch 1978.) The Pathfinder images of dust devils (e.g. Fig. 12) are noisy and required significant processing to allow the dust-loaded vortices to be picked out against the dusty sky (note that unlike most subsequent Mars missions, Pathfinder data was transmitted directly to Earth, there being no relay orbiters yet in place, so the image bandwidth was somewhat more limited). The MER observations, however, were made from an elevated vantage point atop the Columbia 
Fig. 12 Dust devil on Mars observed on the horizon by the Mars Pathfinder imager in 1997. Despite the modest image quality due to JPEG compression artifacts the detection of these features stimulated much modern dust devil research

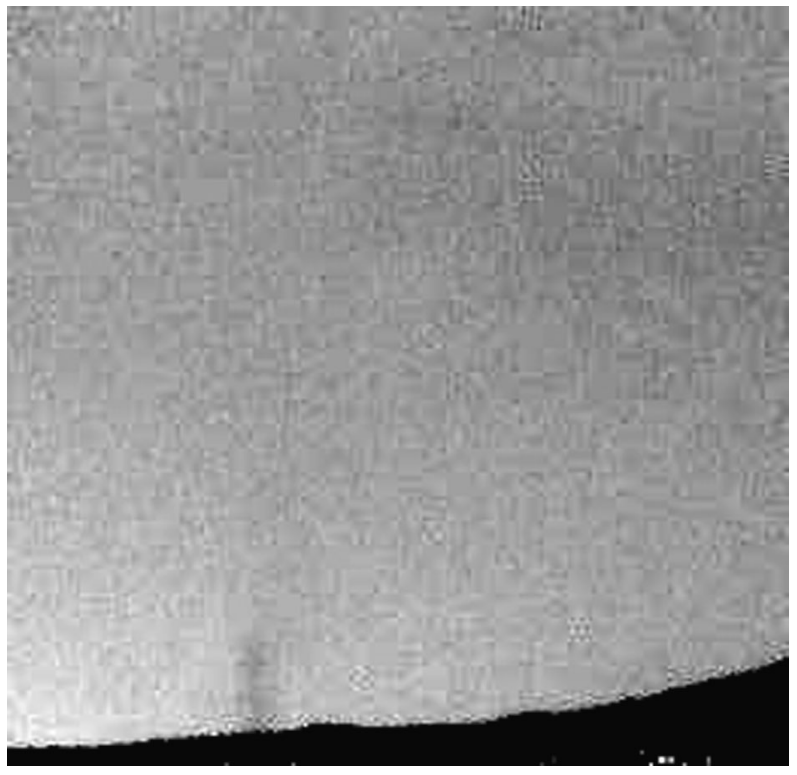

Fig. 13 Dust devils seen on Sol 543 (July 13, 2005) of the Spirit rover mission at Gusev crater. Improvements due to the experience of scientist operators, to the better cameras, and the higher bandwidth, lead to much higher quality images. These are just four frames of a movie sequence, showing the dust devils evolving and migrating from right to left. Note that the dust devils in the foreground have a faster angular motion and are seen only in two frames, while the distant tall devil is seen in all four
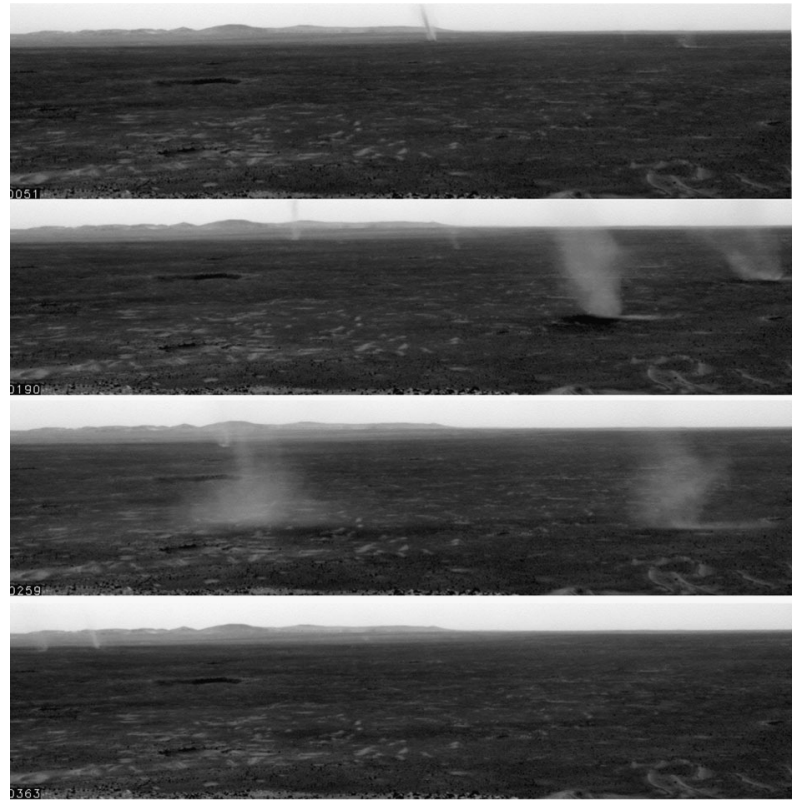

Hills, and, in many images, dust devils on the valley floor are clearly visible against the background terrain beneath. In fact, the images of lines of dust devils marching across the valley are so similar to those of dust devils in arid regions on Earth that it is sometimes hard to tell which planet is being observed.

Further in-situ measurements (see also Chap. 2 by Murphy et al. 2016, and Chap. 10 by Neakrase et al. 2016) and surface observations of dust devils were made by the 2008 Phoenix Mission (Ellehoj et al. 2010), showing that dust devils were active in the martian 
Fig. 14 A dust devil on Mars, photographed by Mars Global Surveyor, climbing the wall of a crater. The long dark, slightly cycloidal streak is the track left by the dust devil, seen as a bright column at the top of the image. A short shadow extends from the base of the devil to the top-right. MSSS MGS image E16-01487

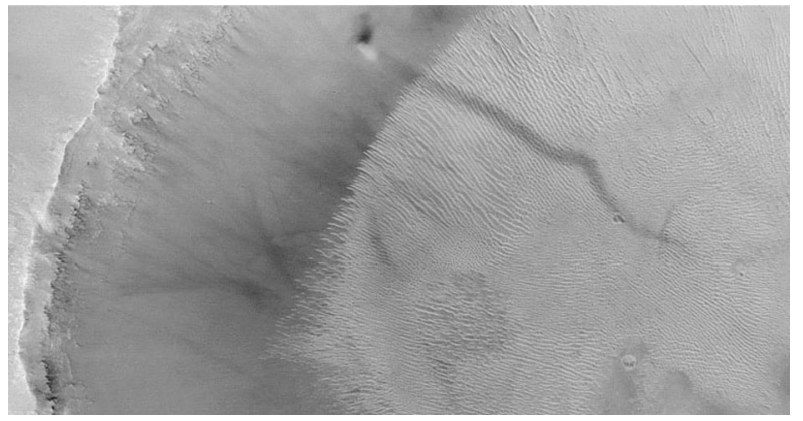

arctic. A disappointment for martian dust devil research, though, was that the 2004 MER missions were not equipped with in-situ meteorology instruments. Hence while Spirit acquired glorious images of dust devils (e.g. Fig. 13), no correlations with vortex wind speeds, pressure and temperature excursions, nor contextual weather data could be made. Although this was rectified for the 2012 (and ongoing at time of writing) Mars Science Laboratory 'Curiosity' Rover, its landing site-Gale Crater-does not appear to be an area with much dust devil activity—only a single visible devil has been reported after several years of observations (Moores et al. 2015).

One of the major differences between dust devil activity on Earth and Mars is that martian dust devils often leave clear traces of their passage across the surfaces they move overwhich is almost never the case on Earth - in the form of linear, curvilinear and even curlicueshaped albedo markings. Dust devil tracks (see review Chapter by Reiss et al. 2016) were first recognized in Viking Orbiter images and interpreted to be 'tornado' tracks (Grant and Schultz 1987-their transient nature was recognized by comparison with Mariner 9 images; they were not suggesting moist tornados of course, but rather "baroclinic wave passage through an area of instability can trigger convective uplift and strong shear leading to tornadic-intensity vortex formation. On Mars in the late summer, the occurrence of atmospheric instability, a deep convective layer, and onset of baroclinic wave passage represent a similar situation"). However, with the arrival of the Mars Global Surveyor mission, and with it the Mars Orbiter Camera (MOC) providing narrow-angle images of $\sim 2 \mathrm{~m} /$ pixel, it soon became clear that these dark (and occasionally bright) lineaments were formed by dust devils: one noted MOC image showing a dust devil 'caught in the act' of forming a track (Fig. 14; Edgett and Malin 2000). It was recently noted (Lorenz and Zimbelman 2014see also chapter in this volume by Reiss et al.) that in fact dust devil tracks can be clearly seen-but were not recognized at the time-in Mariner 9 images of Proctor crater in the Hellespontus region of Mars, images in which dunes on Mars were first reported. It was assumed (J. Cutts, personal communication to RL) that these dark markings were simply fissures on the ground filled with dark material.

The MOC dataset also provided the first opportunity to study dust devils as a population-the extensive coverage in time and space of both active dust devils and their tracks leading to several key conclusions, including (i) martian dust devils are, like on Earth, most active in spring and summer (e.g. Whelley and Greeley 2008), (ii) dust devils do not appear to trigger global dust storms on Mars (e.g., Balme et al. 2003a, 2003b) but do contribute to the persisting haziness of Mars' atmosphere (Cantor et al. 2006), (iii) dust devils are more common in some parts of Mars than in others, especially in the Amazonis Planitia region (Cantor et al. 2006). Further discussion on orbital observations of dust devils at Mars is given in the Chapter by Fenton et al. (2016). 
In the last 15 years, martian dust devil data collection has focused on three areas: observations of dust devils tracks from orbit, observations of active dust devils from orbit, and observations and measurements of dust devils from the surface. Recent advances include the first measurements from orbit of horizontal forward velocity of martian dust devils (tens of meters per second, based on multi-image acquisitions from the ESA Mars Express mission; Stanzel et al. 2008; Reiss et al. 2011b and from the NASA Mars Reconnaissance Orbiter mission; Reiss et al. 2014) and, again from orbit, of wind speeds in martian dust devils, using comparison of the overlapping (but temporally slightly separated) RGB image strips in colour "HiRISE" images (wind speeds of $20-30 \mathrm{~ms}^{-1}$ were measured; Choi and Dundas 2011).

As for in-situ measurements on landers, while wind speed data have been limited (see chapter by Murphy et al.) the detection of vortices - at least some of which are dust-ladenin the long time-series of pressure measurements from the Pathfinder (1997-Murphy and Nelli 2002) and Phoenix (2008-Ellehoj et al. 2010) landers allowed for the first time the systematic evaluation of the vortex population (Lorenz 2012) and its comparison with visual observations of dust devils (Lorenz and Reiss 2015). For many years-indeed since Ryan and Lucich (1983) and until only recently-the high-time resolution meteorological data needed to detect vortices was better at Mars than at Earth. Mars data have stimulated much numerical modeling work, applying LES methods (e.g. see Chap. 7 by Spiga et al. 2016) at high spatial resolutions. An outstanding question remains-much more so at Mars than Earth-how the dust is actually lifted, since (as recognized by Ryan 1964) the thin Martian atmosphere requires very high wind speeds to overcome weight and cohesion of dust. Various solutions have been proposed, including 'sandblasting' by larger particles (Greeley 2002), and the 'Delta-P' (suction) effect (Balme and Greeley 2006).

\section{Applications and Relevance of Dust Devil Research}

The motivations for Mars and Earth dust devil research are several. Most obviously, 'because they are there' - dust devils are one of the most dynamic observable features of the Martian environment. Their transient nature makes them 'interesting' objects to study and chase on Earth, an appeal which has motivated much unfunded casual research. In this section we list some other motivations and applications of dust devil studies

\subsection{Dust Devils as Dust Injectors into the Atmosphere}

Dust in the terrestrial and Martian atmospheres is important for several reasons (e.g. Knippertz and Stuut 2014; Read and Lewis 2004). Dust aerosols interact with radiation through scattering and absorption of shortwave radiation and through absorption and re-emission of longwave radiation. In the terrestrial atmosphere, dust particles act as ice and cloud condensation nuclei and can therefore influence cloud properties and precipitation. Moreover, the removal of dust from the soil, and its redeposition elsewhere, can be important in transporting toxins (see later), nutrients, minerals and carbon, thereby influencing continental and marine ecosystems as well as animals and humans. For example, Saharan dust is known to be an important nutrient source for the Amazon forest (e.g. Bristow et al. 2010). Not least, dust presents an air quality concern, thereby directly affecting human life.

Although the importance of dust in the terrestrial and martian climates is evident, the contribution of dust devils to the Earth and Mars dust budgets is uncertain. On Earth, the first estimate by Koch and Renno (2005) was that dust devils may contribute by about $35 \%$ 
to the total dust burden. More recent estimates suggest a contribution of about a factor of 10 less ( 3.4\%, Jemmett-Smith et al. 2015).

On Mars, a stronger focus has been on the contribution of dust devils to the dust cycle, leading to the development of dust devil parameterizations in Mars global climate models (e.g. Newman et al. 2002). While dust devils are no longer implicated in the formation of large-scale dust storms (and indeed their occurrence is anticorrelated, since dust-loading attenuates the convective instability that drives dust devils), dust lofting by dust devils is believed to be a significant contributor to Mars atmospheric dust loading. However, the need for model calibration against observed dust loadings, leads to uncertainties in the relative contributions of dust devils in comparison to other dust generating mechanisms.

Dust devil occurrence frequencies and associated dust transport can be assessed through a variety of methods, including in situ observations, remote sensing, and modeling. Results based on the different perspectives are synthesized in Chap. 11 of this volume (Klose et al. 2016) to provide a comprehensive picture on the role of dust devils in the terrestrial and martian climates, and the dust-lifting process is reviewed in Chap. 10 by Neakrase et al. (2016).

\subsection{Formation of Dust Devil Tracks-The Martian Climate 'Memory'}

The martian atmosphere is rather thin, and responds quickly to changes in solar heating (e.g. Goody and Belton 1967). It is thus in fact comparatively easy to model, more so than the Earth. All else being equal, one Martian year should look very much like the next, since the atmosphere is too thin to convey much information over long periods. This is in sharp contrast to the Earth, where many multiannual cycles exist due to heat stored in the oceans, a prominent example being the Pacific Decadal Oscillation.

Yet there are substantial interannual variations in Martian weather, notably in the occurrence or not of large dust storms. It seems the distribution of dust on the surface may be a principal controlling factor, and it has been observed that large-scale albedo changes on the Martian surface (e.g. Geissler 2005-although see also Szwast et al. 2006) are often the result of accumulated dust devil tracks (see Chapter by Reiss et al. 2016). Furthermore, these albedo changes are enough to cause variations in modeled temperatures and winds (Fenton et al. 2007). Thus, dust devils may be responsible for much of the variability in the Martian climate- they are a cause as well as an effect.

\subsection{Atmospheric Electricity and Chemistry}

The generation of strong electric fields by dust devils on Earth is well-documented, and electric field measurements are planned at Mars-see the Chap. 11 by Harrison et al. (2016).

A possible consequence of triboelectric charging on Mars, and the resulting corona discharge, is the generation of oxidizing chemicals, notably peroxides and ozone. These are important in that the nondetection of organic compounds by Viking (setting the stage for a sterile, dead world) may have been due to the presence of oxidants in the soil, and indeed the Phoenix lander discovered oxidizing perchlorates (e.g. Hecht et al. 2009). The association of the smell of ozone with electrical discharge is well-known, so this idea (Atreya et al. 2006) seems plausible. It is worth recalling Baddaley's observations of century and a half ago, where evidence of ozone was noted (see earlier). 
Table 3 Dust devil and Tornado statistics compiled from US National Weather Service Hazards reports

\begin{tabular}{|c|c|c|c|c|c|c|}
\hline & $\begin{array}{l}\text { Dust } \\
\text { devil } \\
\text { death }\end{array}$ & $\begin{array}{l}\text { Dust } \\
\text { devil } \\
\text { injury }\end{array}$ & $\begin{array}{l}\text { Dust devil } \\
\text { damage } \\
(\$ M)\end{array}$ & $\begin{array}{l}\text { Tornado } \\
\text { death }\end{array}$ & $\begin{array}{l}\text { Tornado } \\
\text { injury }\end{array}$ & $\begin{array}{l}\text { Tornado } \\
\text { damage } \\
(\$ M)\end{array}$ \\
\hline 2001 & & 1 & & 40 & 743 & 637 \\
\hline 2002 & & & & 55 & 968 & 1 \\
\hline 2003 & 1 & 3 & 0.1 & 54 & 1087 & 1281 \\
\hline 2004 & & 5 & & 35 & 396 & 549 \\
\hline 2005 & & & & 38 & 537 & 503 \\
\hline 2006 & & 1 & & 67 & 990 & 759 \\
\hline 2007 & & & & 81 & 659 & 1407 \\
\hline 2008 & 1 & 14 & 0.06 & 126 & 1714 & 1865 \\
\hline 2009 & & 3 & 0.23 & 31 & 351 & 584 \\
\hline 2010 & & & 0.06 & 45 & 699 & 1135 \\
\hline 2011 & & 8 & 0.03 & 553 & 5483 & 9492 \\
\hline 2012 & & 2 & 0.27 & 70 & 822 & 1649 \\
\hline Total & 2 & 37 & 0.75 & 1195 & 14449 & 19862 \\
\hline Average & 0.17 & 3.08 & 0.06 & 100 & 1204 & 1655 \\
\hline
\end{tabular}

\subsection{Dust Devil Hazard}

Damage and discomfort due to dust devils has been noted since Greek and Roman times earlier in this paper. In the modern world, dust devils, and dry convection generally, can present a hazard to aviation. Typically this is due to sudden changes in wind speed and direction, although sometimes reduced visibility is a factor too. As discussed earlier, some studies in this direction were undertaken in Australia. Lorenz and Myers (2005) review US air accident reports, finding around 100 incidents in the NTSB Air Accident database 19952005 pointing to dust devils as a contributing factor, and four fatal accidents.

An informal survey of news media and the Internet reveals a number of reports of injury due to dust devils. Usually these are associated with lightweight structures-barns, tents, children's bouncy castles and parachutes are often the mechanism by which a sudden wind can cause injury. In one instance, a vehicle in South Africa lost control on encountering a dust devil and an astronomer was killed. In another, a US airline pilot was out jogging, and apparently took shelter from a dust devil by a wooden barn, which collapsed, killing her. Table 3 summarizes injuries, deaths and damage from US National Weather Service (NWS) statistics.

It is seen that the damage and casualties due to dust devils are between two and three orders of magnitude less than those associated with tornados. It is interesting that the area swept by tornados of a given pressure (the intensity on the Fujita scale of a tornado is associated with a speed range, which can be equated with a dynamic pressure, since these vertical systems are in roughly cyclostrophic balance) can be plotted (Fig. 15) on a diagram together with pressure drop encounter statistics from dust devil surveys. The weight loading of various structures (which can be equated with the dynamic pressure required to lift them) is also shown. Clearly, tornados are associated with much stronger pressures, but occur much more seldom. The death rate by dust devil (including parachuting and air accidents) is crudely $\sim 10$ in $\sim 30$ years, or adopting a mean population for the period of $\sim 300$ million, about 0.001 death per year per million. 
Fig. 15 The cumulative frequency that a spot will encounter a vortex of a given intensity, defined by a pressure drop. Dust devil vortex encounter frequencies in summer on Eldorado Playa in Nevada determined by a high-resolution pressure record in Lorenz and Lanagan (2014) are plotted as circles; NWS statistics of tornado mean swept area and intensity as defined in the text are plotted as diamonds. Weight loadings for various objects are noted by dashed lines

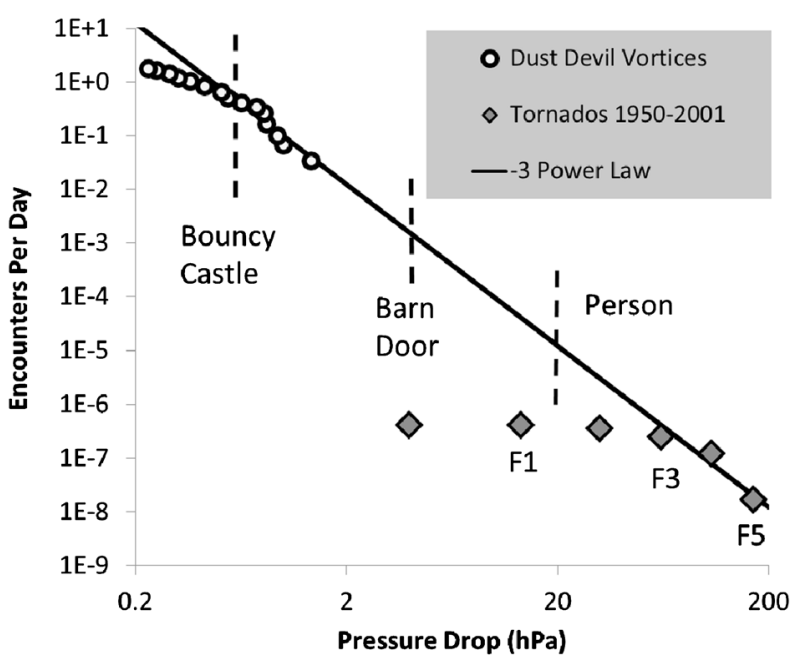

In addition to prompt injury, dust devils may adversely affect human health via injection of pathogens, toxins or irritants into the air (see Morman and Plumlee 2014). A particular concern in the USA is 'Valley Fever' wherein airborne fungal spores from the soil may be inhaled and lead to infection by Coccidioidomycosis, usually with minor symptoms but occasionally pneumonia, joint pain and fatige (e.g. Hector and Laniado-Laborin 2005). It may be noted that the dust at Eldorado Playa, near Boulder City, Nevada, USA—a popular field site for dust devil studies — has been documented (Buck et al. 2013) to contain large amounts of amphibolite, a carcinogenic natural asbestos.

On Mars, in principle, dust devils might be associated with wind extremes that could be problematic for landers or rovers during their descent and landing phases. This is a particular concern for parachute-borne vehicles, which would respond quickly to the wind shear associated with dust devil vortices.

\subsection{Mars Solar Power and Planetary Protection}

There is a direct impact on the operation of spacecraft on the surface of Mars, in that dust progressively accumulates on up-facing surfaces, such as solar arrays. Indeed, the Pathfinder mission observed a steady $0.28 \%$ per day decline in solar power due to dust deposition. This trend guided expectations that later missions (notably the Mars Exploration Rovers) might survive only $\sim 90$ days. However, periodic sudden increases in solar power occurred due to 'clearing events' which swept the arrays clean. Lorenz and Reiss (2015) found that not only did these events seasonally coincide with the start of observed dust devils, but they occurred at a rate consistent with the vortex encounter rates measured by pressure drops on Pathfinder and Phoenix, extrapolated to a dust-lifting threshold intensity. Thus dust devils appear to significantly influence the capabilities of Mars surface assets.

Sand and dust transport on vehicles on the surface of Mars also has a possibly surprising relevance, in that stringent requirements (ultimately mandated by the UN Outer Space Treaty of 1967) on cleanliness and contamination control in order to comply with Planetary Protection policies. These ensure that bacteria or other contaminants are not introduced into Martian environments where they might flourish and disrupt efforts to detect extant or fossil life on Mars. The possibility exists that abrasive particles brought and/or removed by 
dust devils, might scour spacecraft surfaces on the upper part of the vehicle. Since these upper surfaces might not normally be thought to have contact with the Martian ground, these transport processes may demand additional cleaning or bioassay during mission preparation.

\subsection{Dust Devils as Dynamical Objects}

Like more general convective structures, such as the cells in Rayleigh-Benard convection, dust devils are interesting self-organized thermally-driven systems which deserve study as emergent entities. While they might be seen merely as parts of a convecting boundary layer, they can be usefully and accurately considered as discrete structures.

The dynamical structure of dust devils is of interest from a purely fluid-mechanical standpoint, and many studies of analytic models, numerical models and laboratory-scale vortices have been made. There are furthermore useful analogies between dust devils and tornado and other vortices.

A heat-engine formalism by Renno et al. (1998), analogous to similar thermodynamic studies of hurricanes, has been useful in reconciling the temperature perturbations seen in dust devils with the resultant pressure and velocity fields.

Statistical studies of dust devil populations have found that their observed diameters and heights, observed pressure drops, and the widths of dust devil tracks, have highly-skewed distributions, that can be fit by power-laws or other functions (e.g. Lorenz 2011; Kurgansky 2006). There exists an association of power law statistics with self-organized criticality and other forced physical systems. Thus dust devils are of interest from a more general statisti$\mathrm{cal} /$ physical standpoint.

\section{Dust Devils in Culture}

The very name 'dust devil' suggests an association with the occult, shared with the Arabic term 'djinn', appealing to the notion that dust devils conjure themselves out of thin air.

Because dust devils may have both clockwise and anticlockwise sense of rotation there was a belief among native people (Indians) that dust devils with one predefined sense of rotation correspond to a good genius and of opposite one to an evil spirit. Amazingly, both the native people in Chile, and the Navajo in the USA, about $10000 \mathrm{~km}$ distant from the Atacama Desert, have essentially the same belief in this respect.

The occurrence of dust devils in India has a long history, and they are a regular phenomenon in arid regions such as those found in the Hyderabad-Karnatak region. Whilst they are accepted nowadays as commonplace atmospheric phenomenon, in rural Indian farming areas old superstitions relating to dust devils still persist; some farmers working in fields still fear dust devils and will hold their children and belongings flat on the ground until it passes.

Like many evocative phrases, 'dust devil' has been appropriated by other fields of endeavour. 'Dust Devils' is a common name for school sports teams in desert areas of the USA. 'Dust Devil' is the title of a thriller novel by Roger Smith, set in South Africa, and is also that of a violent 1992 horror movie set in Namibia, but aside from scenes at the real-world ghost town of Kolmanskop (notable for being overrun by sand dunes) has no meteorological significance. Dust storms on Mars are a common feature in science fiction movies set on that planet, and dust devils are seen prominently in the popular 2015 movie 'The Martian'. It may be noted that scientific publication of tests of dust penetration into 


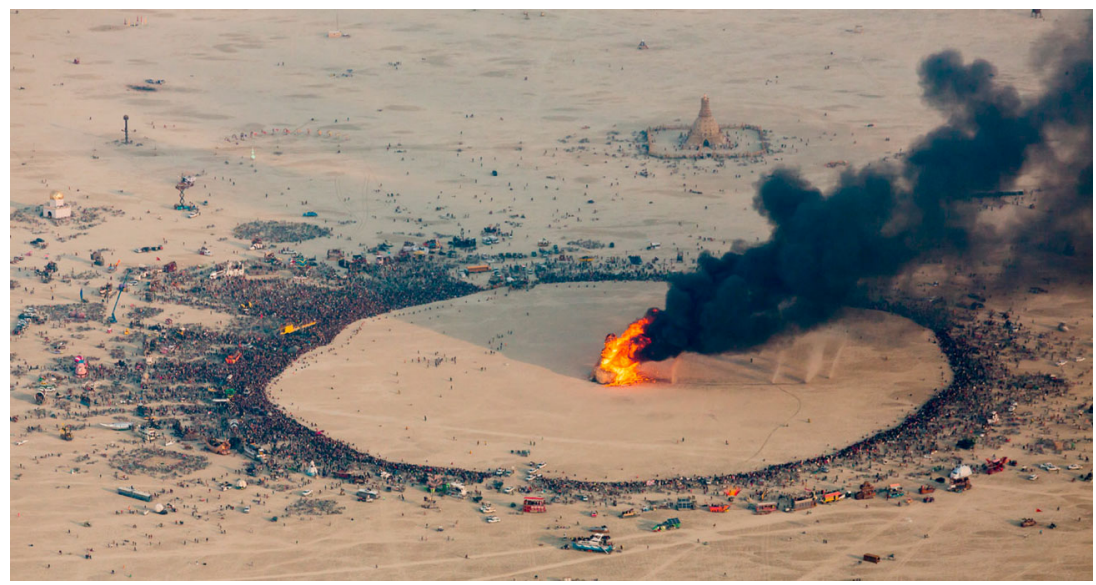

Fig. 16 Aerial view of dust devils at the 2014 Burning Man festival in the USA. This counterculture event is held on a playa which frequently sees dust devils (a web search will find many excellent videos and photos). This aerial image is notable in showing four dust devils apparently triggered by the updraft of the smoke plume from the burning icon. Note the vehicles for scale. Image by Duncan Rawlinson (duncan.co CC Attribution-NC license)

space suit designs for Martian surface operation was made possible by the entertainment industry (Gaier et al. 2010), being tested with simulated dust devils during the production of a documentary 'Storm Worlds'.

A prominent counterculture festival 'Burning Man' is held annually on a remote playa in the Nevada desert, culminating in its eponymous bonfire. Dust devils are frequently encountered at this location, with participants sometimes chasing them on bicycles or on foot. On some occasions, dust devils are actually triggered (see Fig. 16) by the smoke plume from the fire. Another cultural influence of dust devils is the film "Tornado" (2010) by the Belgianborn artist Francis Alys in Mexico, who possibly suggests the chaotic airflow in a dust devil as a metaphor for politics in that country. As reviewed by Rooney (2011), "the sight of his lean frame racing towards the twisters is at once ridiculous and hysterical-blithe qualities that quickly give way to gravitas as the artist physically enters the eye of the storm. Inside, chaos reigns and Alys, unprotected except for his handheld camera, is enveloped and pummeled by flying bits of sand, dust and dirt."

On a lighter note, 'Dust Devil' is the title of a US children's book (and should not be confused with the aforementioned crime novel). Finally, towards the end of a popular children's book (written in Swedish by Finnish author Tove Jansson and published in 1946) "Comet in Moominland", the heroes are lifted in the air by a "cyclone". The illustrations of the book reveal that this "cyclone" is only small in scale and there is no mention of rain. Also several other similar whirlwinds are seen in the illustration of the book. One of the characters, Snufkin, explains that they are caused by heating of the ground by the radiation of an approaching comet. Because of this formation mechanism, the whirlwind mentioned in "Comet in Moominland" should perhaps be classified as a gigantic dust devil instead of a cyclone or tornado. Comets are not traditionally associated with aeolian phenomena, but the discovery of ripples on the surface of a comet just prior to the workshop (Thomas et al. 2015) that stimulated this review paper reminds us that in science we must, as children do naturally, keep an open mind. 


\section{Conclusions}

We have reviewed the history of dust devil research. Dust devils have been studied in a range of countries since the mid-19th century, initially somewhat informally in connection with other rotating wind systems. Instrumented studies of dust devils in their own right begin in earnest in the 1960s, perhaps in connection with nuclear weapons programs. Mars exploration emerged as a major stimulus of dust devil research, initially in the late 1960s, but again in the early 21 st century.

Dust devils present an occasional terrestrial hazard, roughly 2-3 orders of magnitude less severe than tornados. Their role in terrestrial dust-lifting is probably not dominant, but may be significant at Mars. Dust devils appear to be a significant factor in surface albedo changes on Mars, and the removal of dust from lander or rover solar panels by dust devils is an important issue in spacecraft power management and operations. Dust devils engage the public and have interesting properties, both in their individual dynamics and as a population, which are appealing topics of scientific investigation.

Acknowledgements The work of R. Lorenz was supported by NASA Mars Fundamental Research Program grant NNX12AI04G "Quantitative Study of Dust Devils". Several reviewers and reviewing editors provided copious improvements to the paper.

Open Access This article is distributed under the terms of the Creative Commons Attribution 4.0 International License (http://creativecommons.org/licenses/by/4.0/), which permits unrestricted use, distribution, and reproduction in any medium, provided you give appropriate credit to the original author(s) and the source, provide a link to the Creative Commons license, and indicate if changes were made.

\section{References}

Anonymous, Dancing dervishes or dust whirls. Mon. Weather Rev. 30, 316 (1902)

A. Ansmann, M. Tesche, P. Knippertz, E. Bierwirth, D. Althausen, D. Müller, O. Schulz, Vertical profiling of convective dust plumes in southern Morocco during SAMUM. Tellus B 61(1), 340-353 (2009)

B. Atalay, K. Wamsley, Leonardo's Universe: The Renaissance World of Leonardo Da Vinci (National Geographic, Washington, 2009)

S.K. Atreya, A.-S. Wong, N.O. Renno, W.M. Farrell, G.T. Delory, D.D. Sentman, S.A. Cummer, J.R. Marshall, S. Rafkin, D. Catling, Oxidant enhancement in martian dust devils and storms: implications for life and habitability. Astrobiology 6, 439-450 (2006)

P.F.H. Baddeley, Whirlwinds and Dust Storms of India (Bell, London, 1860)

M. Balme, R. Greeley, Dust devils on Earth and Mars. Rev. Geophys. 44, RG3003 (2006). doi:10.1029/ 2005RG000188

M. Balme, A. Hagermann, Particle lifting at the soil-air interface by atmospheric pressure excursions in dust devils. Geophys. Res. Lett. 33(19) (2006). doi:10.1029/2006GL026819

M. Balme, S. Metzger, M. Towner, T. Ringrose, R. Greeley, J. Iversen, Friction wind speeds in dust devils: a field study. Geophys. Res. Lett. 30(16), 1830 (2003a). doi:10.1029/2003GL017493

M.R. Balme, P.L. Whelley, R. Greeley, Mars: dust devil track survey in Argyre Planitia and Hellas Basin. J. Geophys. Res. 108(E8), 5086 (2003b). doi:10.1029/2003JE002096

F. Bell, Dust Devils and Aviation. Report. Meteorol. Note, vol. 27 (Aust. Bur. of Meteorol, Melbourne, 1969)

D. Bowker, Meteorology and the ancient Greeks. Weather 66(9), 249-251 (2011)

C.S. Bristow, K.A. Hudson-Edwards, A. Chappell, Fertilizing the Amazon and equatorial Atlantic with West African dust. Geophys. Res. Lett. 37(14) (2010)

B.J. Buck, D. Goossens, R.V. Metcalf, B. McLaurin, M. Ren, F. Freudenberger, Naturally occurring asbestos: potential for human exposure, Southern Nevada, USA. Soil Sci. Soc. Am. J. 77(6), 2192-2204 (2013)

E. Budde, Eine Beobachtung kleiner Tromben. Z. Österr. Ges. Meteorol. 18, 462-465 (1883)

B.A. Cantor, K.M. Kanak, K.S. Edgett, MOC observations of Martian dust devils and their tracks (September 1997 to January 2006) and evaluation of theoretical vortex models. J. Geophys. Res. 111, E12002 (2006)

D.S. Choi, C.M. Dundas, Measurements of Martian dust devil winds with HiRISE. Geophys. Res. Lett. 38(24) (2011). doi:10.1029/2011GL049806 
K.S. Edgett, M.C. Malin, Martian dust raising and surface albedo controls: thin, dark (and sometimes bright) streaks and dust devils in MGS high-resolution images. Lunar Planet. Sci. [CD-ROM], XXXI, Abstract 1073

M.D. Ellehoj, H.P. Gunnlaugsson, P.A. Taylor, H. Kahanpa, K.M. Bean, B.A. Cantor, B.T. Gheynani, L. Drube, D. Fisher, A.-M. Harri, C. Holstein-Rathlou, M.T. Lemmon, M.B. Madsen, M.C. Malin, J. Polkko, P.H. Smith, L.K. Tamppari, W. Weng, J. Whiteway, Convective vortices and dust devils at the Phoenix Mars mission landing site. J. Geophys. Res. 115, E00E16 (2010)

L.K. Fenton, P.E. Geissler, R.M. Haberle, Global warming and climate forcing by recent albedo changes on Mars. Nature 446(7136), 646-649 (2007)

L. Fenton, D. Reiss, M. Lemmon, B. Marticorena, S. Lewis, B. Cantor, Orbital observations of dust lofted by daytime convective turbulence. Space Sci. Rev. (2016, this issue). doi:10.1007/s11214-016-0243-6

W. Ferrel, Meteorological researches, part II. Cyclones, tornados and waterspouts. Am. J. Sci. 22(127), 33-48 (1881)

W.D. Flower, Sand devils. London Meteorol. Off. Prof. Notes 5(71), 1-16 (1936)

B. Franklin, Letter to Peter Collinson, dated Philadelphia, August 25, 1755 (see e.g. http://www.islandnet. com/ see/weather/history/bfrank1.htm, downloaded 1/21/2016)

C. Fujiwara, Y. Fujiyoshi, Detection of "invisible waterspout" using 3D scanning Doppler lidar. SOLA 10, 127-130 (2014). doi:10.2151/sola.2014-026

C. Fujiwara, K. Yamashita, M. Nakanishi, Y. Fujiyoshi, Dust devil-like vortices in an urban area detected by a 3D scanning Doppler lidar. J. Appl. Meteorol. Climatol. 50, 534-547 (2011). doi:10.1175/ 2010JAMC2481.1

C. Fujiwara, K. Yamashita, Y. Fujiyoshi, Observed effect of mesoscale vertical vorticity on rotation sense of dust devil-like vortices in an urban area. SOLA 8, 25-28 (2012). doi:10.2151/sola.2012-007

J.R. Gaier, P.G. de Leon, P. Lee, T. McCue, E. Hodgson, J. Thrasher, Preliminary testing of a pressurized space suit and candidate fabrics under simulated Mars dust storm and dust devil conditions, in 40th International Conference on Environmental Systems, International Conference on Environmental Systems ICES (2010), AIAA 2010-6247

P.E. Geissler, Three decades of Martian surface changes. J. Geophys. Res. 110, E02001 (2005)

P. Gierasch, R.M. Goody, A model of a Martian great dust storm. J. Atmos. Sci. 30, 749-762 (1973)

R.M. Goody, M.J.S. Belton, Radiative relaxation times for Mars: a discussion of Martian atmospheric dynamics. Planet. Space Sci. 15, 247-256 (1967)

C.G. Grant, Dust devils in the sub-Arctic. Weather 4, 402-403 (1949)

J.A. Grant, P.H. Schultz, Possible tornado-like tracks on Mars. Science 237, 883-885 (1987)

R. Greeley, Saltation impact as a means for raising dust on Mars. Planet. Space Sci. 50, 151-155 (2002)

R. Greeley et al., Active dust devils in Gusev crater, Mars: observations from the Mars exploration rover spirit. J. Geophys. Res. 111, E12S09 (2006)

R. Greeley et al., Gusev crater, Mars: observations of three dust devil seasons. J. Geophys. Res. 115, E00F02 (2010)

Z.L. Gu, Wind-Blown Dust: Near Surface Gas-Solid Two-Phase Turbulent Flow (Science Press, Beijing, 2010) (in Chinese)

Z.L. Gu, Y.Z. Zhao, Y. Li et al., Numerical simulation of dust lifting within dust devils-Simulation of an intense vortex[J]. J. Atmos. Sci. 63(10), 2630-2641 (2006)

Z.L. Gu, W. Wei, Y.Z. Zhao, An overview of surface conditions in numerical simulations of dust devils and the consequent near-surface air flow fields. Aerosol Air Qual. Res. 10, 272-281 (2010)

Z.L. Gu, W. Wei, J.W. Su et al., The role of water content in triboelectric charging of wind-blown sand[J]. Sci. Rep. 3, 1337 (2013)

R.G. Harrison, E. Barth, F. Esposito, J. Merrison, F. Montmessin, K.L. Aplin, C. Borlina, J.J. Berthelier, G. Déprez, W.M. Farrell, I.M.P. Houghton, N.O. Renno, K.A. Nicoll, S.N. Tripathi, M. Zimmerman, Applications of electrified dust and dust devil electrodynamics to Martian atmospheric electricity. Space Sci. Rev. (2016, this issue). doi:10.1007/s11214-016-0241-8

M.H. Hecht et al., Detection of perchlorate and the soluble chemistry of martian soil at the Phoenix lander site. Science 325(5936), 64-67 (2009)

R. Hector, R. Laniado-Laborin, Coccidioidomycosis-a fungal disease of the Americas (2005). PLoS Med. 2(1). doi:10.1371/journal.pmed.0020002

J. Herschel (ed.), A Manual of Scientific Enquiry (Cambridge University Press, New York, 1851). Prepared for the Use of Her Majesty's Navy and Adapted for Travellers in General, reprinted in 1976

G.D. Hess, K.T. Spillane, Characteristics of dust devils in Australia. J. Appl. Meteorol. 29, 498-507 (1990)

G.D. Hess, K.T. Spillane, R.S. Lourensz, Atmospheric vortices in shallow convection. J. Appl. Meteorol. Climatol. 27, 305-317 (1988)

R. Hesse, Short-lived and long-lived dust devil tracks in the coastal desert of southern Peru. Aeolian Res. 5, 101-106 (2012) 
H.Y. Inoue, K. Kusunoki, W. Kato, H. Suzuki, T. Imai, T. Takemi, K. Bessho, M. Nakazato, S. Hoshino, W. Mashiko, S. Hayashi, T. Fukuhara, T. Shibata, H. Yamauchi, O. Suzuki, Finescale Doppler radar observation of a tornado and low-level misocyclones within a winter storm in the Japan Sea coastal region. Mon. Weather Rev. 139, 351-369 (2011). doi:10.1175/2010MWR3247.1

J. Ito, H. Niino, Particle image velocimetry of a dust devil observed in a desert. SOLA 10, 108-111 (2014). doi:10.2151/sola.2014-022

R.L. Ives, Behavior of dust devils. Bull. Am. Meteorol. Soc. 28, 168-174 (1947)

T. Jefferson, Notes on the State of Virginia, Monticello, VA (1787)

B.C. Jemmett-Smith, J.H. Marsham, P. Knippertz, C.A. Gilkeson, Quantifying global dust devil occurrence from meteorological analyses. Geophys. Res. Lett. 42(4), 1275-1282 (2015)

G. Kennan, A trip to the Altai mountains. Science 7, 18-22 (1886)

M. Klose, B. Jemmett-Smith, H. Kahanpää, M. Kahre, P. Knippertz, M. Lemmon, S. Lewis, R. Lorenz, L. Neakrase, C. Newman, M. Patel, D. Reiss, A. Spiga, P. Whelley, Dust devil sediment transport: From lab to field to global impact. Space Sci. Rev. (2016, this issue)

P. Knippertz, J.-B. Stuut, Mineral Dust: A Key Player in the Earth System (Springer, New York, 2014)

J. Koch, N.O. Renno, The role of convective plumes and vortices on the global aerosol budget. Geophys. Res. Lett. 32(18) (2005)

H. Koschmieder, Zur Trombenbildung. Arch. Meteorol. Geophys. Bioklimatol., Ser. A 4, 203-219 (1951)

M.V. Kurgansky, Steady-state properties and statistical distribution of atmospheric dust devils. Geophys. Res. Lett. 33, L19S06 (2006)

M. Kurgansky, R. Lorenz, N. Renno, T. Takemi, W. Wei, Z. Gu, Dust devil steady-state structure from a fluid dynamics perspective. Space Sci. Rev. (2016, this issue)

M.V. Kurgansky, A. Montecinos, V. Villagran, S.M. Metzger, Micrometeorological conditions for dust-devil occurrence in the Atacama Desert. Bound.-Layer Meteorol. 138(2), 285-298 (2011)

R.L. Lambeth, On the measurement of dust devil parameters. Bull. Am. Meteorol. Soc. 47, 522-526 (1966)

W. Lammert, Wirbel-Staubsturm. Meteorol. Z. 15, 279 (1947)

Z. Le, Dust devil in Gobi Desert of Southern Xinjiang province[J]. Meteorol. Mon. 04, 33 (1983) (in Chinese)

X.J. Lei, Y.L. Li, J.W. Du et al., Analysis on the spatio-temporal distribution and daily change rule of cyclone and dust devil in Shaanxi. J. Catastrophology 20(02), 99-101 (2005) (in Chinese)

E. Less, Sandhose in der Nähe von Berlin. Meteorol. Z. 26, 274-275 (1891)

J.P. Letzmann, Richtlinien zur Erforschung von Tromben, Tornados, Wasserhosen und Kleintromben (Guidelines for research on tornados, waterspouts, and whirlwinds), Klimatologische Kommission, IMO Publ., vol. 38, ed. by E. Ijdo (1939), pp. 91-110. Secretariat de l'Organisation Meteorologique Internationale. Available online at: http://www.tordach.org/pdf/letzwww.pdf

R. Lorenz, On the statistical distribution of dust devil diameters. Icarus 215(1), 381-390 (2011)

R.D. Lorenz, Pressure drops in dust devils: Earth and Mars. Planet. Space Sci. 60, 370-375 (2012)

R. Lorenz, The longevity and aspect ratio of dust devils: effects on detection efficiencies and comparison of landed and orbital imaging at Mars. Icarus 226(1), 964-970 (2013)

R.D. Lorenz, Vortex encounter rates with fixed barometer stations: Comparison with visual dust devil counts and large eddy simulations. J. Atmos. Sci. 71, 4461-4472 (2014)

R.D. Lorenz, D. Christie, Dust devil signatures in infrasound records of the international monitoring system. Geophys. Res. Lett. 42(6), 2009-2014 (2015)

R.D. Lorenz, P.D. Lanagan, A barometric survey of dust devil vortices on a desert playa. Bound.-Layer Meteorol. 53, 555-568 (2014). doi:10.1007/s10546-014-9954-y

R.D. Lorenz, M.J. Myers, Dust devil hazard to aviation: a review of United States air accident reports. J. Meteorol. 30(298), 178-184 (2005)

R. Lorenz, J. Radebaugh, Dust devils in thin air: vortex observations at a high elevation Mars analog site in the Argentinian puna. Geophys. Res. Lett. 43 (2016). doi:10.1002/2015GL067412

R.D. Lorenz, D. Reiss, Solar panel clearing events, dust devil tracks, and in-situ vortex detections on Mars. Icarus 248, 162-164 (2015)

R. Lorenz, J. Zimbelman, Dune Worlds: How Wind-Blown Sand Shapes Planetary Landscapes (Springer, New York, 2014)

M.A. Lucanus, The Civil War I-X (Pharsalia) (Heinemann, London, 1926) (English Translation by J. Duff; the original was in $65 \mathrm{AD}$ )

J.P. Mason, M.R. Patel, S.R. Lewis, The retrieval of optical properties from terrestrial dust devil vortices. Icarus 231, 385-393 (2014)

H. Maurer, Entstehung einer Sandhose. Meteorol. Z. 51, 275 (1934)

J.B. McGinnigle, Dust whirls in North-West Libya. Weather 21, 272-276 (1966)

J.R. McGinnigle, A note on observed dust-whirl damage at Nicosia, Cyprus. Meteorol. Mag. 99, 118-122 (1970) 
S.M. Metzger, J.R. Carr, J.R. Johnson, T.J. Parker, M.T. Lemmon, Dust devil vortices seen by the Mars Pathfinder camera. Geophys. Res. Lett. 26, 2781-2784 (1999)

S. Metzger, M. Kurgansky, A. Montecinos, V. Villagran, H. Verdejo, Chasing dust devils in Chile's Atacama Desert, in 41st Lunar and Planetary Science Conference, Houston, TX, March 2010 (2010), Abstract \#2564

A. Miethe, Das Entstehen der Windhosen. Prometheus 10, 795-796 (1899)

J.E. Moores, M.T. Lemmon, H. Kahanpää, S.C. Rafkin, R. Francis, J. Pla-Garcia, A.R. Vasavada, Observational evidence of a suppressed planetary boundary layer in northern Gale Crater, Mars as seen by the Navcam instrument onboard the Mars Science Laboratory rover. Icarus 249, 129-142 (2015)

S. Morman, G. Plumlee, Dust and human health, in Mineral Dust: A Key Player in the Earth System, ed. by P. Knippertz, J.-B. Stuut (Springer, New York, 2014), pp. 385-410

J.R. Murphy, S. Nelli, Mars Pathfinder convective vortices: frequency of occurrence. Geophys. Res. Lett. 29(23), 18-1-18-4 (2002)

J. Murphy, K. Steakley, F. Esposito, G. Deprez, H. Kahanpaa, M. Lemmon, M. Patel, M. Balme, N. Murdoch, L. Neakrase, P. Whelley, R. Lorenz, Field measurements of terrestrial and Mars dust devils. Space Sci. Rev. (2016, this issue)

T.A. Mutch, The Martian Landscape, NASA Special Publication SP-425 (1978)

L.D.V. Neakrase, M.R. Balme, F. Esposito, T. Kelling, M. Klose, J.F. Kok, B. Marticorena, J. Merrison, M. Patel, G. Wurm, Particle lifting processes in dust devils. Space Sci. Rev. (2016, this issue)

F.M. Neubauer, Thermal convection in the Martian atmosphere. J. Geophys. Res. 71, 2419-2426 (1966)

C.E. Newman, S.R. Lewis, P.L. Read, F. Forget, Modeling the Martian dust cycle: 1. Representations of dust transport processes. J. Geophys. Res. 107(E12), 5123 (2002). doi:10.1029/2002JE001910

A.M.C. Oke, D. Dunkerley, N.J. Tapper, Willy-willies in the Australian landscape: sediment transport characteristics. J. Arid Environ. 71(2), 216-228 (2007a)

A.M.C. Oke, N.J. Tapper, D. Dunkerley, Willy-willies in the Australian landscape: the role of key meteorological variables and surface conditions in defining frequency and spatial characteristics. J. Arid Environ. 71(2), 201-215 (2007b)

C. Piazzi-Smyth, Tenerife: An Astronomer's Experiment, or, Specialities of a Residence Above the Clouds (Lovell Reeve, London, 1858), p. 180

S. Raasch, T. Franke, Structure and formation of dust devil-like vortices in the atmospheric boundary layer: a high resolution numerical study. J. Geophys. Res. 116, D16120 (2011). doi:10.1029/2011JD016010

S. Rafkin, B. Jemmet-Smith, L. Fenton, J. Ito, D. Tyler, R. Lorenz, Dust devil formation. Space Sci. Rev. (2016, this issue)

P. Read, S. Lewis, The Martian Climate Revisited: Atmosphere and Environment of a Desert Planet (Springer, New York, 2004)

D. Reiss, J. Raack, A.P. Rossi, G. Di Achille, H. Hiesinger, First in-situ analysis of dust devil tracks on Earth and their comparison with tracks on Mars. Geophys. Res. Lett. 37, L14203 (2010). doi:10.1029/ 2010GL044016

D. Reiss, J. Raack, H. Hiesinger, Bright dust devil tracks on Earth: implications for their formation on Mars. Icarus 211, 917-920 (2011a)

D. Reiss, M. Zanetti, G. Neukum, Multitemporal observations of identical active dust devils on Mars with the High Resolution Stereo Camera (HRSC) and Mars Orbiter Camera (MOC). Icarus 215, 358-369 (2011b)

D. Reiss, M.I. Zimmerman, D.C. Lewellen, Formation of cycloidal dust devil tracks by redeposition of coarse sands in southern Peru: implications for Mars. Earth Planet. Sci. Lett. 383, 7-15 (2013)

D. Reiss, A. Spiga, G. Erkeling, The horizontal motion of dust devils on Mars derived from CRISM and CTX/HiRISE observations. Icarus 227, 8-20 (2014)

D. Reiss, L. Neakrase, L. Fenton, P. Whelley, T. Statella, M. Zimmerman, A.P. Rossi, M. Balme, Dust devil trails. Space Sci. Rev. (2016, this issue)

N.O. Renno, M.L. Burkett, M.P. Larkin, A simple thermodynamical theory for dust devils. J. Atmos. Sci. 55, 3244-3252 (1998)

T.J. Ringrose, M.C. Towner, J.C. Zarnecki, Convective vortices on Mars: a reanalysis of Viking Lander 2 meteorological data, sols 1-60. Icarus 163, 78-87 (2003)

K. Rooney Francis alÿs: A story of deception, the Brooklyn Rail, July-August (2011). http://www. brooklynrail.org/2011/07/artseen/francis-als-a-story-of-deception-july11, downloaded 1/4/2016

A.P. Rossi, L. Marinangeli, The first terrestrial analogue to Martian dust devil tracks found in Tenere Desert, Niger. Geophys. Res. Lett. 31(6) (2004)

J.A. Ryan, Notes on the Martian yellow clouds. J. Geophys. Res. 69(18), 3759-3770 (1964)

J.A. Ryan, J.J. Carroll, Dust devil wind velocities: mature state. J. Geophys. Res. 75, 531-541 (1970)

J.A. Ryan, R.D. Lucich, Possible dust devils, vortices on Mars. J. Geophys. Res. 88, 11005-11011 (1983) 
A. Schläfli, Über Staubtromben und den "Samum” in Unter-Mesopotamien. Z. Österr. Ges. Meteorol. 5, 469-472 (1870)

P.C. Sinclair, Some preliminary dust devil measurements. Mon. Weather Rev. 22(8), 363-367 (1964)

P.C. Sinclair, On the rotation of dust devils. Bull. Am. Meteorol. Soc. 46, 388-391 (1965)

P.C. Sinclair, General characteristics of dust devils. J. Appl. Meteorol. 8, 32-45 (1969)

P.C. Sinclair, The lower structure of dust devils. J. Atmos. Sci. 30, 1599-1619 (1973)

J.T. Snow, T.M. McClelland, Dust devils at white sands missile range, New Mexico: 1. temporal and spatial distributions. J. Geophys. Res., Atmos. 95(D9), 13707-13721 (1990)

A. Spiga, F. Forget, A new model to simulate the Martian mesoscale and microscale atmospheric circulation: validation and first results. J. Geophys. Res., Planets 114(E2) (2009). doi:10.1029/2008JE003242

A. Spiga, E. Barth, Z. Gu, F. Homann, J. Ito, B. Jemmett-Smith, M. Klose, S. Nishizawa, S. Raasch, S. Rafkin, T. Takemi, D. Tyler, W. Wei, Large-eddy simulations of dust devils and convective vortices (2016)

K.T. Spillane, G.D. Hess, Fair weather convection and light aircraft, helicopter, and glider accidents. J. Aircr. 25, 55-61 (1988)

C. Stanzel, M. Pätzold, D.A. Williams, P.L. Whelley, R. Greeley, G. Neukum (HRSC Co-Investigator Team), Dust devil speeds, directions of motion and general characteristics observed by the Mars express high resolution stereo camera. Icarus 197(1), 39-51 (2008)

M.A. Szwast, M.I. Richardson, A.R. Vasavada, Surface dust redistribution on Mars as observed by the Mars global surveyor and Viking orbiters. J. Geophys. Res. 111, E11008 (2006)

M. Tachikawa, K. Deguchi, A whirlwind attacked an athletic meeting. Wind Eng., JAWE 1987(31), 1316 (1987). Available at: https://www.jstage.jst.go.jp/article/jawe1982/1987/31/1987_31_13/_article (in Japanese with English figure captions)

P.C. Thomas, P.J. Gierasch, Dust devils on Mars. Science 230, 175-177 (1985)

N. Thomas et al., The morphological diversity of comet 67P/Churyumov-Gerasimenko. Science 347, 6220 (2015)

M.C. Towner, Characteristics of large Martian dust devils using Mars Odyssey thermal emission imaging system visual and infrared images. J. Geophys. Res., Planets 114(E2) (2009). doi:10.1029/2008JE003220

D.M. Tratt, M.H. Hecht, D.C. Catling, E.C. Samulon, P.H. Smith, In situ measurements of dust devil dynamics: toward a strategy for Mars. J. Geophys. Res. 108(E11), 5116 (2003). doi:10.1029/2003JE002161

A. von Humboldt, Ansichten der Natur, 3rd edn. (J.G. Cotta, Stuttgart, 1849), p. 26

A. Wegener, Staubwirbel auf Island. Meteorol. Z. 31, 199-200 (1914)

P.L. Whelley, R. Greeley, The distribution of dust devil activity on Mars. J. Geophys. Res., Planets 113(E7) (2008). doi:10.1029/2007JE002966

R.E. Wyett, Pressure drop in a dust devil. Mon. Weather Rev. 82, 7 (1954) 